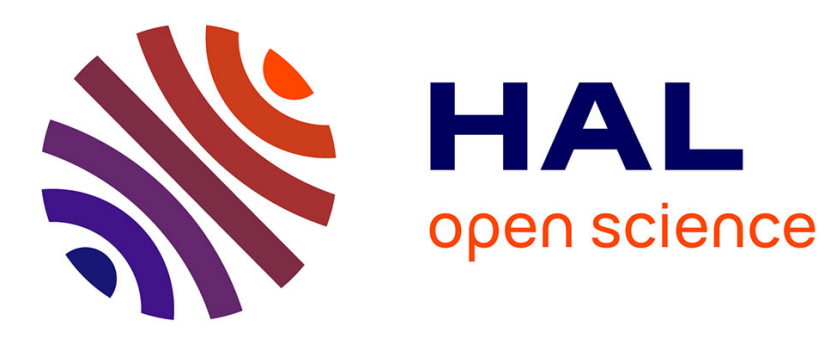

\title{
Redox Reducible and Hydrolytically Degradable PEG-PLA Elastomers as Biomaterial for Temporary Drug-Eluting Medical Devices
}

Simona Rupnik, Sytze Buwalda, Stéphane Dejean, Audrey Bethry, Xavier Garric, Jean Coudane, Benjamin Nottelet

\section{To cite this version:}

Simona Rupnik, Sytze Buwalda, Stéphane Dejean, Audrey Bethry, Xavier Garric, et al.. Redox Reducible and Hydrolytically Degradable PEG-PLA Elastomers as Biomaterial for Temporary DrugEluting Medical Devices. Macromolecular Bioscience, 2016, 10.1002/mabi.201600132 . hal-01369303

\section{HAL Id: hal-01369303 https://hal.science/hal-01369303}

Submitted on 29 Nov 2019

HAL is a multi-disciplinary open access archive for the deposit and dissemination of scientific research documents, whether they are published or not. The documents may come from teaching and research institutions in France or abroad, or from public or private research centers.
L'archive ouverte pluridisciplinaire HAL, est destinée au dépôt et à la diffusion de documents scientifiques de niveau recherche, publiés ou non, émanant des établissements d'enseignement et de recherche français ou étrangers, des laboratoires publics ou privés. 
Redox reducible and hydrolytically degradable PEG-PLA elastomers as biomaterial for temporary drug eluting medical devices

Simona Rupnik, Sytze Buwalda, Stéphane Dejean, Audrey Bethry, Xavier Garric, Jean Coudane, Benjamin Nottelet*

Institute of Biomolecules Max Mousseron (IBMM) UMR 5247, Department of Artificial Biopolymers, CNRS, University of Montpellier, ENSCM.

Faculté de Pharmacie, 15 avenue Charles Flahault BP14491, 34093 Montpellier cedex 5,

France

* benjamin.nottelet@umontpellier.fr 


\begin{abstract}
With the aim to develop biomaterials for temporary medical devices, a series of novel reducible and/or degradable elastomers have been prepared from PLA- $b$-PEG- $b$-PLA copolymers photo-crosslinked with diallyl sulfide or pentaerythritol tetrakis(3mercaptopropionate). Thermal and mechanical properties, including elastic limit and Young modulus, were assessed. Degradation was then evaluated under standard hydrolytic conditions. Reducibility of a selected elastomer was then illustrated using 2-mercaptoethanol or glutathione as reducing agents. The redox-sensitivity of the selected elastomer and the possibility to modulate the degradability were shown. Considering drug eluting elastomeric devices applications, anti-inflammatory drug ibuprofen loading was illustrated with the two simplest elastomer formulations. A rapid or slow linear release was observed as a function of the low or high molecular weight of the triblock pre-polymers. Finally, the cytocompatibility of the degradable elastomers was assessed with regard to their potential to favor or inhibit L929 murine fibroblasts proliferation as a function of the hydrophilicity/hydrophobicity of the triblock copolymers.
\end{abstract}

KEYWORDS elastomers, polyesters, degradation, redox, drug release, medical device 


\section{INTRODUCTION}

The interest for novel biomaterials that present elastomeric properties faces a rapid growth due to the development of medical devices, tissue engineering and/or repair and scaffolding techniques. In particular, degradable elastomers represent an attractive class of biomaterials for biomedical applications due to the possibility to match their mechanical properties with body tissues, while accessing a broad range of degradation rates that can be adjusted directly by polymer chain natures, crosslink density and crosslink nature. As a result of the high potential of biomedical applications and of the possibility to finely tune their properties, it is therefore no surprise that a large diversity of degradable elastomers is proposed as illustrated in recent reviews. ${ }^{[1,2]}$

Among them, one can distinguish between thermoplastic elastomers, that are physically crosslinked, and chemically crosslinked elastomers. Degradable thermoplastic elastomers being semi-crystalline, they undergo a heterogeneous degradation and release profiles as well as non-linear loss of properties with degradation, which limits their use in tissue engineering and controlled drug delivery applications. ${ }^{[3,4]}$ On the other hand, degradable crosslinked elastomers generally degrade by combination of bulk and surface erosion, which assures a constant 3D structure throughout the hydrolysis process as well as a linear drug release profile than can be of benefit for soft tissue engineering applications. ${ }^{[5]}$ In the recent years, crosslinked elastomers have therefore attracted attention for controlled delivery of drugs and proteins. ${ }^{[6-11]}$ Besides their structure, ie. thermoplastic vs. crosslinked elastomers, another distinction can be done in terms of materials used. Considering the objectives and the existing industrial elastomeric materials, most described degradable elastomers are based on polyesters or polyurethane backbones, although polycarbonate, mainly poly(1,3-trimethylene carbonate), ${ }^{[12]}$ can also be found. Degradable elastomers are therefore generally produced by polycondensations/polyadditions (eg. poly(polyol sebacate) and poly(diol citrate), 
diisocyanate and $\alpha, \omega$-dihydroxyoligoesters $)^{[13-18]}$ or by thermal-or photo-radical curing of double bonds bearing prepolymers (eg. (meth)acrylated or fumarate containing polyesters $)^{[19-}$ ${ }^{22]}$. In the frame of biomedical applications and drug eluting systems, some parameters should however be taken in consideration for the selection of optimal elastomeric materials. A first one is the biocompatibility of the materials: for that reason, it is generally recognized that isocyanate-based materials should be banned and many researches toward nonisocyanate PU are currently undertaken. ${ }^{[23,24]} \mathrm{A}$ second one is the drug friendly character of the production process: in this regard harsh synthesis and crosslinking conditions such as high reaction temperature, long reaction time, and vacuum that are often needed during the preparation of thermo-cured should be avoided. Last but not least, the regulatory aspects for the medical applications market, ie. the approval of the proposed elastomers by the regulatory agencies (EMA, FDA etc.) is mandatory.

This combination of features led us to investigate the possibility to use aliphatic copolyesters derivatives as potential elastomeric biomaterials for temporary medical devices. Being approved for biomedical applications poly( $\varepsilon$-caprolactone) (PCL), poly(glycolic acid) (PGA) or poly(lactic acid) (PLA) and their block copolymers are indeed the most frequently utilized degradable synthetic polymers in this field. We therefore described recently various approaches to yield aliphatic polyester elastomers both on the thermoplastic ${ }^{[25,26]}$ and the photo-crosslinked network approaches based on methacrylate ${ }^{[27]}$ and thiol-yne chemistries ${ }^{[28]}$. In particular, our aim is to fulfill the gap between existing degradable polymeric networks with weak mechanical properties, typically hydrogels and stiffer ones, typically used for bone repair. ${ }^{[29]}$ Indeed, soft elastomeric materials with typical Young's moduli in the range 1 to 500 $\mathrm{MPa}$ pave the way to all soft tissue applications ranging from skin (typically $1 \mathrm{MPa}$ ) to ligament (typically few hundreds of MPa), whereas hydrogels and thermosets are more suited for extracellular matrix and bone applications, respectively. ${ }^{[30]}$ In addition, besides 
mechanical properties, the degradation time frame is also important for applications. Aliphatic polyesters are known to exhibit various degradation kinetics, that can be easily modulated by controlling the macromolecular parameters (crystallinity, hydrophobicity of the ester units, molecular weight), ${ }^{[31]}$ or the nature of the crosslinkers, ${ }^{[27]}$ which makes same appropriate candidates for elastomeric degradable biomaterials.

Finally, considering the development of smarter biomaterials, one should also consider stimuli-responsiveness in order to control the life-time of the considered materials. In this regard, reducible bonds that may be cleaved by biologically relevant reducers, like glutathione, have recently attracted attention among polymer chemists. Glutathione (GSH) is considered to be the major thiol-disulfide redox buffer of the cell. ${ }^{[32]}$ It plays important roles in the maintenance of intracellular redox state and as an antioxidant, cellular protectant and regulatory signaling molecule. It has been reported that in the cytosol and nuclei, the concentration of GSH reaches $10 \mathrm{mM}$, while outside the cell the concentration reduces to about $2-20 \mu \mathrm{M} \cdot{ }^{[33]}$ In particular, in vivo studies on mice showed that in the tumor tissues at least 4-fold higher concentrations of GSH were present, compared to the normal tissue. ${ }^{[34,35]}$ As a consequence, GSH-responsive polymers have been mainly developed for drug delivery approaches. For example redox-releasing micelles, redox-unveiling nanoparticles and other nanoscales assemblies have been described. ${ }^{[36,37]}$ On the other hand, only few examples of reducible elastomers have been reported so far. One can cite polydisulfide networks proposed as photo-healable or self-healable materials, ${ }^{[38,39]}$ or reducible PNIPAAm ${ }^{[40]}$ or PEG hydrogels. ${ }^{[11-43]}$ However, to the best of our knowledge, apart from the PCL-SS-PCL network reported by our group ${ }^{[44]}$ none of these structures combine elastomeric properties, degradability (even if excretable) and biocompatibility. PCL-SS-PCL network was generated under oxidative conditions starting from thiol-functional PCL. Although interesting, one 
limitation with regard to medical device applications is however the rather limited availability of the starting material (gram scale).

In the present work, we aim therefore at combining in degradable elastomers various features that would be of advantage for soft tissue-related medical devices. In more details we report on elastomers combining i) a large availability of starting materials thanks to the use of industrially relevant PLA-PEG copolymers, ii) a mild crosslinking via photochemistry, iii) a tunable and/or bimodal degradation thanks to the combination of homogenous hydrolytic degradability provided by PLA-PEG copolymers, and of stimuli-responsive degradability thanks to reducible disulfide bonds of diallyl sulfide, an agent known for its chemopreventive activity against some human cancers, ${ }^{[45-47]}$ and finally iv) drug loading ability with linear drug release profile.

\section{EXPERIMENTAL SECTION}

\subsection{Materials}

Dihydroxy poly(ethylene glycol) $\left(\mathrm{PEG}_{1 \mathrm{~K}} \mathrm{Mn}=1000 \mathrm{~g} / \mathrm{mol} ; \mathrm{PEG}_{2 \mathrm{~K}} \mathrm{Mn}=2000 \mathrm{~g} / \mathrm{mol}\right)$, tin(II) 2-ethylhexanoate $(\mathrm{Sn}(\mathrm{Oct}) 2,95 \%)$, triethylamine (99\%), diallyl sulfide (AS, 97\%), pentaerythritol tetrakis(3-mercaptopropionate) (PETMP, > 95\%), 1-hydroxycyclohexyl benzophenone $\quad\left(\right.$ Irgacure ${ }^{\circledR} 184, \quad$ I184, 99\%), 2,2-dimethoxy-2-phenylacetophenone (Irgacure®651， I651，99\%), methacryloyl chloride (> 97\%), diethyl ether and dichloromethane were purchased from Sigma-Aldrich (St-Quentin Fallavier, France). D,Llactide (D,L-LA) was purchased from Purac (Lyon, France). PrestoBlueTM, modified Eagle's medium (MEM), horse serum, penicillin, streptomycin, Glutamax and Dulbecco's Phosphate Buffered Saline (DBPS) were purchased from Invitrogen (Cergy Pontoise, France). Cellstar® polystyrene tissue culture plates (TCPS) were purchased from Greiner Bio-One (Courtaboeuf, 
France). All chemicals and solvents were used without purification with exception of dichloromethane which was dried over calcium hydride before distillation and use.

\subsection{Characterizations}

Molecular weights were determined by Size Exclusion Chromatography (SEC) using a Waters equipment fitted with a $60 \mathrm{~cm}$ long $5 \mu \mathrm{m}$ mixed C PLgel column as the stationary phase, tetrahydrofuran (THF) at $1 \mathrm{ml} / \mathrm{min}$ flow rate as the mobile phase, and a Waters 410 refractometric detector. Typically, polymer $(10 \mathrm{mg})$ was dissolved in THF $(2 \mathrm{ml})$ and the resulting solution was filtered on a $0.45 \mu \mathrm{m}$ Millipore filter before injection of $20 \mu \mathrm{L}$ of sample solution. Mn and $Đ$ were expressed according to calibration using polystyrene standards. ${ }^{1} \mathrm{H}$ and ${ }^{13} \mathrm{C}$ NMR spectra were recorded at room temperature using an AMX300 Bruker spectrometer operating at $300 \mathrm{MHz}$. Deuterated chloroform or deuterated dimethylsulfoxide were used as solvents, and chemical shifts were expressed in ppm with respect to tetramethylsilane (TMS). Infrared spectra were recorded on a Perkin-Elmer Spectrum 100 FT-IR spectrometer. The thermal properties of the polymers were characterized by differential scanning calorimetry (DSC). DSC measurements were carried out under nitrogen on a Perkin Elmer Instrument DSC 6000 Thermal Analyzer. Samples were submitted to a first heating scan to $110{ }^{\circ} \mathrm{C}\left(5^{\circ} \mathrm{C} \cdot \mathrm{min}^{-1}\right)$ followed by a cooling to $-65^{\circ} \mathrm{C}\left(5^{\circ} \mathrm{C} \cdot \mathrm{min}^{-1}\right)$ and a second heating scan to $200{ }^{\circ} \mathrm{C}\left(5^{\circ} \mathrm{C} \cdot \mathrm{min}^{-1}\right)$. Glass transition temperature $(\mathrm{Tg})$ was measured on the second heating ramp. PrestoBlueTM absorption was quantified with a Thermo Scientific Multiscan® FC microplate photometer. 


\subsection{Synthesis of crosslinkable PLA- $b$-PEG- $b$-PLA triblock copolymers}

Methacrylated PLA- $b$-PEG- $b$-PLA triblock copolymers were prepared according to the procedure already reported by our group. ${ }^{[27]}$ In a first step, triblock copolymers with targeted molecular weight of $3300 \mathrm{~g} / \mathrm{mol}$ and $10000 \mathrm{~g} / \mathrm{mol}$ were prepared by adjusting the ratios of D,L-LA with respect to the PEG macroinitiators. PLA-PEG-PLA triblocks were obtained with a typical yield of ca. $90 \%$.

In a second step, PLA- $b$-PEG- $b$-PLA triblock copolymers were reacted with methacryloyl chloride according to the procedure described in our previous work. ${ }^{[27]}$ Methacrylated PLAPEG-PLA triblock copolymers were obtained with a methacrylation yield superior to $70 \%$ and kept in a dark place. ${ }^{1} \mathrm{H}$ NMR $(300 \mathrm{MHz} ; \mathrm{CDCl} 3): \delta(\mathrm{ppm})=6.2$ and $5.6(\mathrm{~s}, 2 \mathrm{H}$, $\mathrm{CH} 2=\mathrm{C}(\mathrm{CH} 3)) 5.2(\mathrm{~m}, 1 \mathrm{H}, \mathrm{CO}-\mathrm{CH}(\mathrm{CH} 3)-\mathrm{O}), 4.3(\mathrm{~m}, 1 \mathrm{H}, \mathrm{CO}-\mathrm{CH}(\mathrm{CH} 3)-\mathrm{OH}$ and $2 \mathrm{H} \mathrm{CH} 2-$ $\mathrm{CH} 2-\mathrm{O}(\mathrm{CO})), 3.6(\mathrm{~s}, 4 \mathrm{H}, \mathrm{CH} 2-\mathrm{CH} 2-\mathrm{O}), 1.9(\mathrm{~s}, 3 \mathrm{H}, \mathrm{CH} 2=\mathrm{C}(\mathrm{CH} 3)) \quad 1.5(\mathrm{~m}, 3 \mathrm{H}, \mathrm{CO}-$ $\mathrm{CH}(\mathrm{CH} 3)-\mathrm{O})$.

Methacrylation efficiency was calculated according to Equation 1.

Methacrylation efficiency $=\frac{\left(\frac{I_{5,7-6,1}}{2}\right)}{\left[\left(\frac{I_{5,7-6,1}}{2}\right)+\left(I_{4,3}-4 \times \frac{I_{3,6}}{D P_{P E G} \times 4}\right)\right]} \quad$ Equation1

\subsection{Elastomers photo-crosslinking}

Typically, methacrylated PLA- $b$-PEG- $b$-PLA triblock copolymers (2.5 g) were dissolved in acetone $(5 \mathrm{~mL})$ with predetermined amounts of Irgacure ${ }^{\circledR} 184$ and/or Irgacure ${ }^{2} 651$ as photoinitiators and diallyl sulfide (A) and/or pentaerythritol tetrakis(3-mercaptopropionate) (P) as crosslinkers. Elastomers formulations are listed in Table 1. The obtained viscous solutions were poured in silicon vessels and let to dry slowly under a hood for 16 hours in the 
dark. The resulting films were further dried at room temperature under reduced pressure $\left(10^{-1}\right.$ bar) for 1 hour. The films obtained were cross-linked for 10 minutes ( 5 minutes for each side) under UV light using DYMAX Light Curing System Model 2000 Flood.

Sol-gel analysis was conducted by swelling the films in $\mathrm{CH}_{2} \mathrm{Cl}_{2}$ at room temperature. Initial $\mathrm{CH}_{2} \mathrm{Cl}_{2}$ was replaced few times by fresh solvent over a $24 \mathrm{~h}$ period to allow full extraction of unreacted prepolymers and crosslinkers. The solvent was removed, the films were dried, and the gel content $(\mathrm{Gc})$ was estimated by calculating the ratio between the films weights before and after extraction.

\subsection{Mechanical analyses of elastomers}

Elastomer samples (typically $12 \times 2 \times 0.6 \mathrm{~mm}$ ) were prepared for tensile tests. Analyses were conducted at $37^{\circ} \mathrm{C}$ on an Instron 4444 tensile machine with a crosshead speed of $5 \mathrm{~mm} / \mathrm{min}$. Each sample was analysed in its dry (D) and hydrated (H) state. Hydration was obtained by soaking samples in a phosphate buffer solution ( $\mathrm{PBS}, \mathrm{pH} \mathrm{7,4)}$ at room temperature for $1 \mathrm{~h}$. Each sample was then analysed in triplicate and Young's modulus (E, MPa), ultimate stress $\left(\sigma_{\text {break }}, \mathrm{MPa}\right)$, ultimate strain $\left(\varepsilon_{\text {break }}, \%\right)$ and elastic limit $\left(\varepsilon_{\text {yield }}, \%\right)$ were expressed as the mean value of the three measurements. E was calculated using the initial linear portion of the stress/strain curve.

\subsection{Elastomers swelling and degradation}

Samples of elastomer films were weighed and placed in phosphate buffer solution (PBS, pH 7.4) at $37^{\circ} \mathrm{C}$. The swelling percentage was calculated based on the initial dry samples weights according to the following equation. 
$Q=\frac{\left(W_{h}-W_{0}\right)}{W_{0}} \times 100 \quad$ Equation 2

where $\mathrm{W}_{\mathrm{h}}$ is the weight of the hydrated sample after $t$ hours in PBS and $\mathrm{W}_{0}$ the initial dry weight of the sample. Each result was expressed as the mean value of three measurements.

Degradation was carried out in $\mathrm{PBS}$ at $37^{\circ} \mathrm{C}$ under stirring for various periods of time. After incubation the sample was gently dried on absorbent paper, weighed and further dried under reduced pressure at $40^{\circ} \mathrm{C}$. The degradation was assessed using water uptake and weight loss. The water uptake was calculated based on the dry samples weights after degradation using the following equation

$$
W U=\frac{\left(W_{h}-W_{d}\right)}{W_{d}} \times 100 \quad \text { Equation } 3
$$

where $\mathrm{W}_{\mathrm{h}}$ is the hydrated weight and $\mathrm{W}_{\mathrm{d}}$ the dry weight of the sample after a defined period of time in PBS. The weight loss was calculated using the following equation

$$
W L=\frac{\left(W_{0}-W_{d}\right)}{W_{0}} \times 100 \quad \text { Equation } 4
$$

where $\mathrm{W}_{\mathrm{d}}$ is the dry weight of the sample after a defined period of time in PBS and $\mathrm{W}_{0}$ the initial dry weight of the sample before degradation. Each result was expressed as the mean value of three measurements.

To evaluate the reducibility of disulfide bonds present in the samples crosslinked with AS, degradation experiments were run under the same conditions by adding 2-mercaptoethanol $(10 \mathrm{mM})$ or glutathione (GSH, $10 \mathrm{mM})$ in PBS. 


\subsection{Drug loading and drug release}

Ibuprofen was chosen as an anti-inflammatory model drug to evaluate the loading and release capacities of the elastomers. In a typical experiment, a $300 \mathrm{mg}$ sample of elastomer was soaked in $10 \mathrm{~mL}$ of a $4 \mathrm{wt} \%$ solution of ibuprofen in acetone under mild shaking. After 24 hours, the sample was withdrawn from the solution and dried under reduce pressure until constant mass was obtained. The loaded sample was weighed $\left(\mathrm{W}_{L S}\right)$. This procedure was done with $\mathrm{n}=6$ for each elastomer.

For release study, ibuprofene-loaded elastomers were immersed in glass vials containing 10 $\mathrm{mL}$ PBS (pH 7.4). The samples were incubated at $37^{\circ} \mathrm{C}$ under mild shaking. Each release experiment was done in triplicate. At predetermined time intervals, the PBS with released ibuprofene was replaced by fresh PBS. The amount of released ibuprofene in PBS was evaluated by HPLC (WatersTM 717 plus Autosampler) using a 50:50 mixture of water:TFA (1000:1) and acetonitrile:TFA (1000:1) at $1 \mathrm{~mL} / \mathrm{min}$ flow rate and a photodiode array detector $\left(\lambda_{\max }=264 \mathrm{~nm}\right)$. Before analysing by HPLC, solutions were filtered and $2 \mathrm{ml}$ of EtOH was added.

For determination of the drug loading, samples $(n=3$ for each elastomer) were soaked in 10 $\mathrm{ml}$ of acetone and let to swell for $48 \mathrm{~h}$ under gentle stirring. Release medium containing ibuprofen was collected and replaced with fresh acetone. The same procedure was repeated 3 times. Collected solutions were gathered before evaporation of solvent under reduced pressure to dryness. Released ibuprofen was then dissolved in $10 \mathrm{ml}$ of PBS/EtOH (50:50) solution for HPLC quantification. 


\subsection{Elastomers cytocompatibility}

Mouse L929 fibroblasts (L929) were cultured in modified Eagle's medium (MEM) containing $10 \%$ horse serum, penicillin $(100 \mu \mathrm{g} / \mathrm{mL})$, streptomycin $(100 \mu \mathrm{g} / \mathrm{mL})$, and Glutamax $(1 \%)$. Elastomer films were disinfected in ethanol (95\%) for 30 minutes before immersion in a solution of sterile PBS containing penicillin and streptomycin $(1 \mathrm{mg} / \mathrm{mL})$ and incubation for 48 hours at $37^{\circ} \mathrm{C}$. Films were then rinsed 3 times with sterile PBS before soaking for 12 hours in sterile PBS. Before drying, swelled sterile elastomers films were stamped to fit the size of the wells of 24-well cell culture plates. The in vitro cytocompatibility of the elastomers was assessed by following the proliferation of L929 on the surface of elastomer films. Films were placed in polystyrene 24-well tissue culture plates (TCPS) and seeded with 50000 cells. Cells proliferation after 1, 2, 3 and 7 days was evaluated using the PrestoBlue ${ }^{\mathrm{TM}}$ assay that reflects the number of living cells present on a surface at a given time point. At scheduled time points, culture medium was removed and replaced by $1 \mathrm{~mL}$ of fresh medium containing $10 \%$ of PrestoBlue ${ }^{\mathrm{TM}}$. After 2 hours of incubation at $37^{\circ} \mathrm{C}$, aliquots of $100 \mu \mathrm{L}$ were taken and analysed for UV absorbance at $570 \mathrm{~nm}$ and $595 \mathrm{~nm}$. All data points and standard deviations correspond to measurements in triplicate. 


\section{RESULTS AND DISCUSSION}

\subsection{Elastomers synthesis and characterizations}

Few years ago, our group reported on PLA $_{50}-b$-PEG- $b$-PLA S0 $_{50}$ based networks exhibiting tunable elastomeric properties and degradability that were controlled by the nature of the crosslinkers. ${ }^{[27]}$ In particular, mechanical properties were close to the ones of soft cartilage or vascular vessels $\left(\mathrm{E} \approx 2-5 \mathrm{MPa}, \varepsilon_{\text {break }}\right.$ up to $90 \%$, $\varepsilon_{\text {yield }}$ up to $30 \%$ ), whereas a linear degradation was observed over 6 months. In the present work, we aim at combining the hydrolytic degradability of this class of elastomers with, on the one hand the highly desired stimuli-responsive crosslinks to gain increased control over the mechanical and degradation behavior of the elastomers, and on the other hand, the facile photoradical thiol-ene addition.

For that purpose, two PLA- $b$-PEG- $b$-PLA triblock copolymers with amorphous PD,L-LA blocks were first synthesized: a low molecular weight triblock $\left(\mathrm{PLA}_{9}-\mathrm{PEG}_{2 \mathrm{k}}-\mathrm{PLA}_{9}, \mathrm{Mn}_{\mathrm{NMR}}=\right.$ $3300 \mathrm{~g} / \mathrm{mol})$ with higher hydrophilicity $(\mathrm{EG} / \mathrm{LA}=2.5)$ and a medium molecular weight triblock $\left(\mathrm{PLA}_{62}-\mathrm{PEG}_{1 \mathrm{k}}-\mathrm{PLA}_{62}, \mathrm{Mn}_{\mathrm{NMR}}=12300 \mathrm{~g} / \mathrm{mol}\right)$ with higher hydrophobicity $(\mathrm{EG} / \mathrm{LA}=$ 0.2). Classical ring opening polymerization of $\mathrm{D}, \mathrm{L}$-lactide using $\mathrm{PEG}_{1 \mathrm{~K}}$ or $\mathrm{PEG}_{2 \mathrm{~K}}$ as a macroinitiator was used. Good control over the polymerization was obtained as shown by the comparison of targeted and experimental molecular weights determined by NMR analyses and by the limited dispersities determined by SEC analyses (Table S1). Chromatograms resulting from SEC analysis were monomodal and used to confirm the absence of PLA homopolymer. The apparent discrepancy between $\mathrm{Mn}_{\mathrm{NMR}}$ and $\mathrm{Mn}_{\mathrm{SEC}}$ is attributed to the amphiphilic character of the block copolymer with higher difference observed with increasing hydrophilicity. ${ }^{[48]}$ 
In a second step photo-crosslinkable triblock copolymers were prepared by reaction between the PLA- $b$-PEG- $b$-PLA triblock copolymers and methacryloyl chloride. Using Equation 1, methacrylation efficiencies were calculated from the integrations of NMR resonance peaks at 6.1 and $5.7 \mathrm{ppm}$ belonging to the alkenyl protons, and at $4.3 \mathrm{ppm}$ belonging to the PEG and non methacrylated PLA chain ends. Methacrylation efficiencies were $70 \%$ and $100 \%$ for $\mathrm{PLA}_{62}-\mathrm{PEG}_{1 \mathrm{k}}-\mathrm{PLA}_{62}$ and $\mathrm{PLA}_{9}-\mathrm{PEG}_{2 \mathrm{k}}-\mathrm{PLA}_{9}$, respectively. A typical NMR spectrum is provided as Supplementary Information (Figure S1). No significant change in molecular weight distribution was found by SEC analyses confirming that triblock copolymers were not degraded under these conditions (Table S1). The lower methacrylation yield for PLA $62^{-}$ $\mathrm{PEG}_{1 \mathrm{k}}-\mathrm{PLA}_{62}$ is assumed to be due to the higher molecular weight making the hydroxyl end groups less accessible for reaction in the copolymer large random coil compared to PLA9$\mathrm{PEG}_{2 \mathrm{k}}-\mathrm{PLA}_{9}$

Table 1. Elastomers formulations

\begin{tabular}{lcccc}
\hline Sample name & $\begin{array}{c}\text { Irgacure®184 } \\
(\text { mol \% / alkene })\end{array}$ & $\begin{array}{c}\text { Irgacure®651 } \\
(\text { mol \% / alkene })\end{array}$ & $\begin{array}{c}\text { PETMP } \\
\text { (mol \% / } \\
\text { alkene) }\end{array}$ & $\begin{array}{c}\text { AD } \\
\text { (mol \% / alkene) }\end{array}$ \\
\hline $\mathrm{E}_{12-\varnothing}$ & 10 & 0 & 0 & 0 \\
$\mathrm{E}_{12-\mathrm{P}}$ & 0 & 10 & 25 & 0 \\
$\mathrm{E}_{12-\mathrm{A}}$ & 10 & 0 & 0 & 25 \\
$\mathrm{E}_{12-\mathrm{P}-\mathrm{A}}$ & 5 & 5 & 12.5 & 12.5 \\
$\mathrm{E}_{3.5-\varnothing}$ & 10 & 0 & 0 & 0 \\
$\mathrm{E}_{3.5-\mathrm{P}}$ & 0 & 10 & 25 & 0 \\
$\mathrm{E}_{3.5-\mathrm{A}}$ & 10 & 0 & 0 & 25 \\
$\mathrm{E}_{3.5-\mathrm{P}-\mathrm{A}}$ & 5 & 5 & 12.5 & 12.5 \\
\hline
\end{tabular}

Elastomeric biomaterials were then prepared with various formulations including the two chosen crosslinkers, namely diallyl sulfide (A) and pentaerythritol tetrakis(3mercaptopropionate) (P) (Scheme 1). In particular, diallyl sulfide was chosen as it is a non toxic garlic-derivative that presents in its free form various benefits for human health including a reported chemopreventive activity against some human cancers such as colon, 
lung and skin cancers. ${ }^{[45-47]}$ Samples were named according to the following system: E was used for elastomer, 12 or 3.5 were used to indicate the molecular weight of the methacrylated triblock copolymer (12000 g/mol or $3500 \mathrm{~g} / \mathrm{mol}), \varnothing, \mathrm{A}$ and $\mathrm{P}$ were used for no crosslinker, diallyl sulfide and pentaerythritol tetrakis(3-mercaptopropionate), respectively.<smiles>CC(C)OCCC(C)(C)O</smiles><smiles>CCCCCCCOC(=O)C(C)OC(C)C(=O)OC(C)(C)C(=O)C(C)(C)O</smiles>
Methacrylation<smiles>C=C(C)C(=O)OC(C)C(=O)OCCOC(=O)C(C)(C)OC(=O)C(=C)C</smiles>

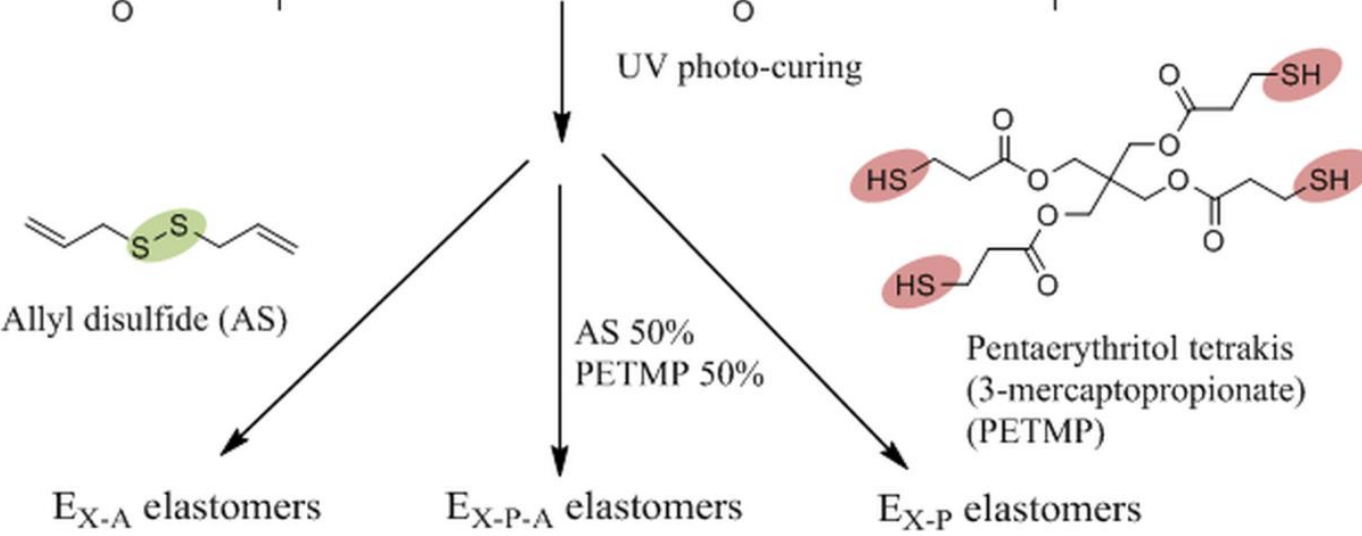

Scheme 1. Formulation of elastomers ( $X=3.5$ or 12 depending on the molecular weight of the initial triblock copolymer). 
Elastomers formulations are listed in Table 1. When present, crosslinkers molar concentrations were fixed to $25 \%$ with respect to the alkene groups. Photo-initiators were selected depending on the nature of the crosslinker: Irgacure ${ }^{\circledR} 184$ was used in combination with diallyl sulfide (acrylic crosslinking), Irgacure® 651 was used in combination with pentaerythritol tetrakis(3-mercaptopropionate) (thiol-ene crosslinking). As little to no influence of photoinitiator was found in our previous work, a low concentration of $10 \%$ of photoinitiator with respect to the alkene groups was chosen. Low concentration should guaranty a higher biocompatibility of the final elastomers although the chosen photoinitiators have long track records in the field of biomaterials. All elastomers were photo-crosslinked under UV (5 min/side) with $75 \mathrm{~mW} / \mathrm{cm}^{2}$ intensity.

Table 2. Elastomers gel content and thermal properties.

\begin{tabular}{lcccc}
\hline \multicolumn{1}{c}{ Sample name } & $\mathrm{Gc}(\%)$ & $\mathrm{Tg}\left({ }^{\circ} \mathrm{C}\right)$ & $\mathrm{Tm}\left({ }^{\circ} \mathrm{C}\right)$ & $\Delta \mathrm{Hm}(\mathrm{J} / \mathrm{g})$ \\
\hline $\mathrm{E}_{12-\varnothing}$ & 97 & 19 & $/$ & $/$ \\
$\mathrm{E}_{12-\mathrm{P}}$ & 97 & 18 & $/$ & $/$ \\
$\mathrm{E}_{12-\mathrm{A}}$ & 96 & 15 & $/$ & $/$ \\
$\mathrm{E}_{12-\mathrm{P}-\mathrm{A}}$ & 96 & 21 & $/$ & $/$ \\
$\mathrm{E}_{3.5-\varnothing}$ & 96 & -12 & 26 & 11 \\
$\mathrm{E}_{3.5-\mathrm{P}}$ & 95 & $\mathrm{nd}^{*}$ & 22 & 4 \\
$\mathrm{E}_{3.5-\mathrm{A}}$ & 93 & $\mathrm{nd}$ & 21 & 10 \\
$\mathrm{E}_{3.5-\mathrm{P}-\mathrm{A}}$ & 92 & $\mathrm{nd}$ & $/$ & $/$ \\
\hline
\end{tabular}

*not determined: of too low intensity to be detected under the analyses conditions

The extent of crosslinking was assessed by determination of the gel contents (Gc). In all samples Gc was superior to $92 \%$ and no significant differences between the formulations was found (Table 2). It is to note that despite a lower methacrylation for $\mathrm{PLA}_{62}-\mathrm{PEG}_{1 \mathrm{k}}-\mathrm{PLA}_{62}$, crosslinking was highly efficient.

For $\mathrm{E}_{12}$ elastomers, a limited increase of $\mathrm{Tg}\left(15^{\circ} \mathrm{C}\right.$ to $\left.21^{\circ} \mathrm{C}\right)$ was observed with crosslinking compared to the initial $\mathrm{Tg}$ value of $15^{\circ} \mathrm{C}$ for methacrylated $\mathrm{PLA}_{62}-\mathrm{PEG}_{1 \mathrm{k}}-\mathrm{PLA}_{62}$ (Table 2 and Table S2). Such a limited increase corresponds to a limited restriction of chains mobility, 
which is in agreement with the looser network expected for longer pre-polymer chains (12000 $\mathrm{g} / \mathrm{mol})$. The highest $\mathrm{Tg}$ value $\left(21^{\circ} \mathrm{C}\right)$ was obtained when both crosslinkers were used. In addition, although the pre-polymer showed a melting temperature of PEG block around $30^{\circ} \mathrm{C}$, no melting temperature was found for $\mathrm{E}_{12}$ elastomers in agreement with the amorphous nature of the PLA blocks and the hindered crystallization of PEG blocks due to the crosslinking. In opposition, for $\mathrm{E}_{3.5}$ elastomers a strong impact of crosslinking was observed on $\mathrm{Tg}$. Starting from $-37^{\circ} \mathrm{C}$ for the pre-polymer, $\mathrm{Tg}$ values reached $-12^{\circ} \mathrm{C}$ for $\mathrm{E}_{3.5-\emptyset}$. This is in agreement with our previous study and with the shorter $(3500 \mathrm{~g} / \mathrm{mol})$ pre-polymer chains. ${ }^{[27]}$ For the three other $\mathrm{E}_{3.5}$ elastomers, $\mathrm{Tg}$ could not be determined. It is our belief that $\mathrm{Tg}$ was either hidden or disturbed by the melting peak around $20^{\circ} \mathrm{C}$, or was of too weak intensity to be observed. The melting temperature of ca. $20^{\circ} \mathrm{C}$ was due to the crystallization of PEG and was ca. $15^{\circ} \mathrm{C}$ lower than the one found for the pre-polymer in agreement with a crystallization made more difficult by the network structure, and with the lower melting enthalpy values compared to the pre-polymer.

\subsection{Elastomers mechanical properties}

Tensile tests were performed to evaluate the mechanical properties of the elastomers with respect to their formulations. Taking into account that the elastomers should be implanted they were studied in both the dry and hydrated state at $37^{\circ} \mathrm{C}$. Results are listed in Table 3.

A clear influence of the molecular weight and composition of the pre-polymer is found. In more details, Young's modulus is inferior to $0.9 \mathrm{MPa}$ for all $\mathrm{E}_{12}$ elastomers and superior to 1.4 MPa for all $\mathrm{E}_{3.5}$ elastomers with a maximal value of $2.2 \mathrm{MPa}$. These values are in the low range for soft tissues (vascular vessel, soft cartilage). The invert is found for all other parameters with higher values of ultimate stress $\left(\sigma_{\text {break }}\right)$, ultimate strain $\left(\varepsilon_{\text {break }}\right)$ and elastic 
limit $\left(\varepsilon_{\text {yield }}\right)$ for $E_{12}$ elastomers compared to $E_{3.5}$ elastomers. In more details, for $E_{3.5}$ elastomers $\sigma_{\text {break }}$ is below $0.9 \mathrm{MPa}, \varepsilon_{\text {break }}$ is below $45 \%$ and $\varepsilon_{\text {yield }}$ is inferior to $25 \%$. These values tend to show that $\mathrm{E}_{3.5}$ elastomers are indeed quite weak materials with low elasticity. Due to the high EG/LA ratio (2.5) $\mathrm{E}_{3.5}$ elastomers behaviour could be compared to some extent to hydrogels. In opposition, $\mathrm{E}_{12}$ elastomers present properties close to the ones of mentioned soft tissues, with $\sigma_{\text {break }}$ in the range 1.1-2.9 MPa, $\varepsilon_{\text {break }}$ in the range $180-340 \%$ and $\varepsilon_{\text {yield }}$ in the range $70-154 \%$. Of particular interest is the uniaxial elastic limit which is above $100 \%$ for most $\mathrm{E}_{12}$ samples making them more appropriate for high deformation applications. They fit the definition of elastomers according to ASTM or ISO norms where some characterizations are done at $100 \%$ strain. $^{[49]}$

Table 3. Elastomers mechanical properties in the dry (D) and hydrated state $(\mathrm{H})$ at $37^{\circ} \mathrm{C}$ (Young's modulus $(E)$, ultimate stress $\left(\sigma_{\text {break }}\right)$, ultimate strain $\left(\varepsilon_{\text {break }}\right)$ and elastic limit $\left(\varepsilon_{\text {yield }}\right)$ )

\begin{tabular}{lcccc}
\hline \multicolumn{1}{c}{ Sample name } & $\mathrm{E}(\mathrm{MPa})$ & $\sigma_{\text {break }}(\mathrm{MPa})$ & $\varepsilon_{\text {break }}(\%)$ & $\varepsilon_{\text {yield }}(\%)$ \\
\hline $\mathrm{E}_{12-\varnothing} \mathrm{D}$ & $0.66 \pm 0.09$ & $1.98 \pm 0.56$ & $200 \pm 49$ & $144 \pm 3$ \\
$\mathrm{E}_{12-\mathrm{P}} \mathrm{D}$ & $0.53 \pm 0.08$ & $1.83 \pm 0.56$ & $314 \pm 25$ & $96 \pm 10$ \\
$\mathrm{E}_{12-\mathrm{A}} \mathrm{D}$ & $0.51 \pm 0.14$ & $1.12 \pm 0.17$ & $192 \pm 1$ & $124 \pm 4$ \\
$\mathrm{E}_{12-\mathrm{P}-\mathrm{A}} \mathrm{D}$ & $0.67 \pm 0.27$ & $1.95 \pm 0.03$ & $242 \pm 9$ & $154 \pm 36$ \\
$\mathrm{E}_{3.5-\varnothing} \mathrm{D}$ & $2.20 \pm 0.28$ & $0.72 \pm 0.05$ & $25 \pm 2$ & $20 \pm 3$ \\
$\mathrm{E}_{3.5-\mathrm{P}} \mathrm{D}$ & $1.58 \pm 0.05$ & $0.87 \pm 0.04$ & $45 \pm 1$ & $25 \pm 4$ \\
$\mathrm{E}_{3.5-\mathrm{A}} \mathrm{D}$ & $2.07 \pm 0.14$ & $0.72 \pm 0.28$ & $15 \pm 5$ & $19 \pm 4$ \\
$\mathrm{E}_{3.5-\text { P-A }} \mathrm{D}$ & $1.63 \pm 0.07$ & $0.56 \pm 0.07$ & $29 \pm 3$ & $21 \pm 3$ \\
\hline $\mathrm{E}_{12-\varnothing} \mathrm{H}$ & $0.87 \pm 0.14$ & $2.88 \pm 0.22$ & $292 \pm 36$ & $139 \pm 43$ \\
$\mathrm{E}_{12-\mathrm{P}} \mathrm{H}$ & $0.67 \pm 0.12$ & $2.07 \pm 0.48$ & $341 \pm 42$ & $72 \pm 3$ \\
$\mathrm{E}_{12-\mathrm{A}} \mathrm{H}$ & $0.61 \pm 0.14$ & $1.46 \pm 0.44$ & $181 \pm 13$ & $74 \pm 7$ \\
$\mathrm{E}_{12-\mathrm{P}-\mathrm{A}} \mathrm{H}$ & $0.44 \pm 0.03$ & $2.59 \pm 0.80$ & $301 \pm 34$ & $133 \pm 18$ \\
$\mathrm{E}_{3.5-\varnothing \mathrm{H}}$ & $1.53 \pm 0.17$ & $0.27 \pm 0.01$ & $21 \pm 18$ & $9 \pm 1$ \\
$\mathrm{E}_{3.5-\mathrm{P}} \mathrm{H}$ & $1.32 \pm 0.41$ & $0.44 \pm 0.01$ & $21 \pm 6$ & $13 \pm 3$ \\
$\mathrm{E}_{3.5-\mathrm{A}} \mathrm{H}$ & $1.88 \pm 0.56$ & $0.51 \pm 0.08$ & $15 \pm 10$ & $7 \pm 2$ \\
$\mathrm{E}_{3.5-\mathrm{P}-\mathrm{A}} \mathrm{H}$ & $1.37 \pm 0.18$ & $0.25 \pm 0.05$ & $11 \pm 4$ & $9 \pm 3$ \\
\hline
\end{tabular}

Hydration had no impact or little impact on the mechanical properties of $E_{12}$ elastomers with exception of $\varepsilon_{\text {break }}$ that was slightly increased, in particular for $\mathrm{E}_{12-\varnothing}(48 \%$ increase). In opposition, for the more hydrophilic $\mathrm{E}_{3.5}$ elastomers hydration led to a limited decrease of 
$\varepsilon_{\text {break }}$ and a strong decrease of $\varepsilon_{\text {yield }}$ of ca. $55 \%$. This result tends to prove that water uptake (see next paragraph) leads to a marked plasticization of the $\mathrm{E}_{3.5}$ elastomers.

Coming to the influence of the crosslinkers, each parameter is influenced differently with respect to the nature of the crosslinker. For the Young's moduli, the elastic limits and ultimate stresses, no significant influence was found, with exception for AS crosslinker that lowered $\sigma_{\text {break }}$ values of $\mathrm{E}_{12}$ of about $40-45 \%$. The most significant effect was observed for ultimate strains, with $\varepsilon_{\text {break }}$ of both $\mathrm{E}_{12}$ and $\mathrm{E}_{3.5}$ being higher with PETMP compared to AS or no crosslinker. This is due to the flexible nature of the ether and thioether bonds with PETMP.

To summarize it is interesting to note that by considering all properties and both the hydrated and dry state, the best suited crosslinker depends on the prepolymer used. For $\mathrm{E}_{12}$ (higher molecular weight, more hydrophobic), the combination of PETMP and AS provides best

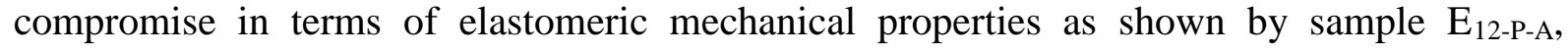
whereas for $\mathrm{E}_{3.5}$ (lower molecular weight, more hydrophilic) it is PETMP that provides best compromise in terms of elastomeric mechanical properties as shown by sample $\mathrm{E}_{3.5-\mathrm{P}}$.

\subsection{Elastomers degradation and reduction}

In the frame of the degradation study, water uptake was first evaluated. As expected, water uptake was slow for the higher molecular weight and more hydrophobic $\mathrm{E}_{12}$ elastomers compared to $E_{3.5}$ elastomers (Figure 1). Evaluation of water uptake was therefore carried out over 6 months for $E_{12}$ but due to their degradation and loss of physical integrity $E_{3.5}$ samples were only analyzed for one month. As can be seen in Figure 1 all samples presented a quasi linear water uptake up to one month for $E_{3.5}$ samples and up to 3 months for $E_{12}$ samples. Above this time point a strong increase of water uptake was observed for $E_{12-\varnothing}$ and $E_{12-P}$. Water uptakes were important for $E_{3.5}$ samples with ca. $150 \%$ after only one week, in agreement with the values previously reported for similar elastomers. ${ }^{[27]}$ In comparison, very 
limited water uptakes were measured for $\mathrm{E}_{12}$ samples with values around $5 \%$ after one week, and only 40 to $70 \%$ after three months. No clear influence of the crosslinkers was observed.

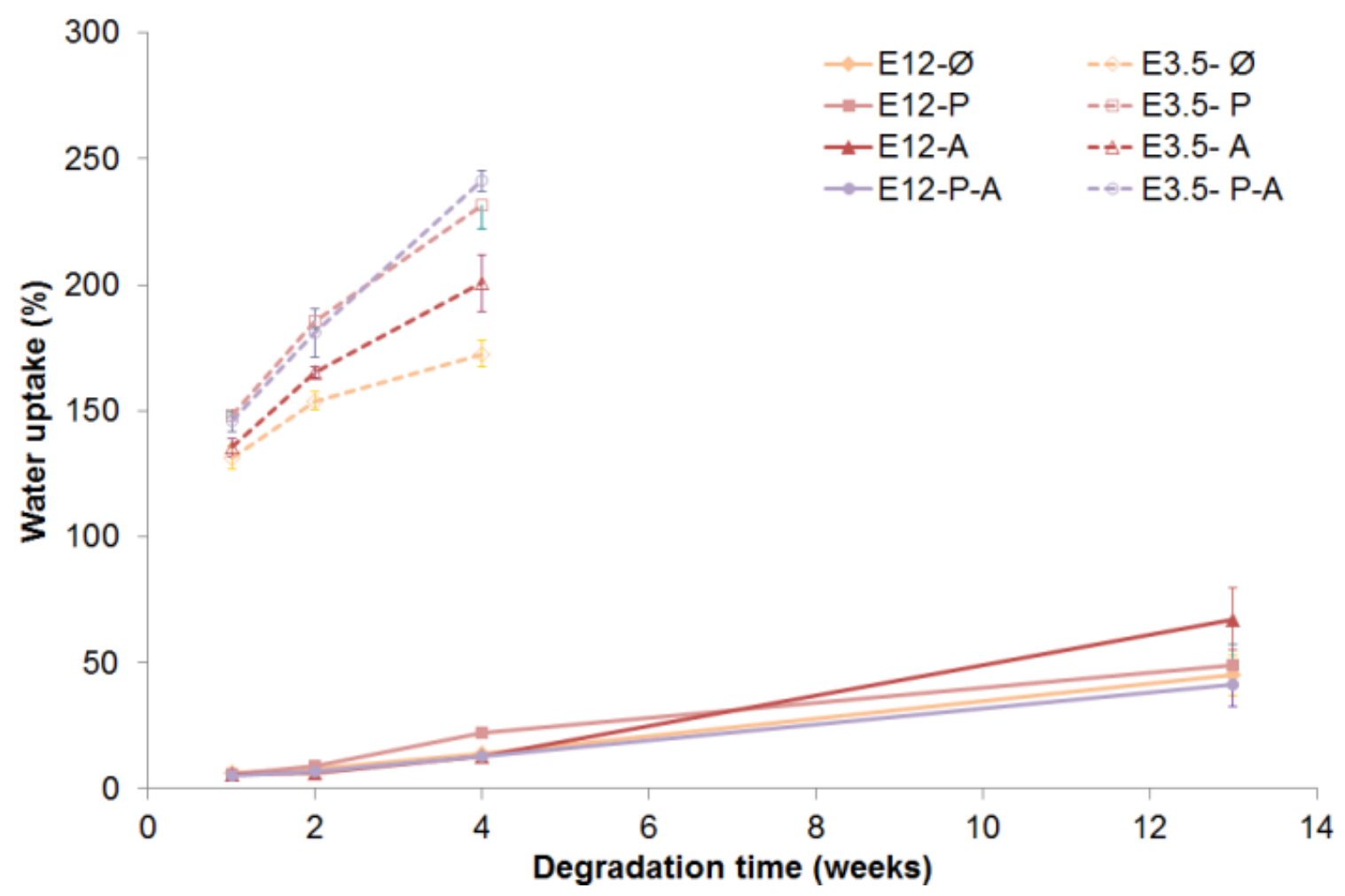

Figure 1. Water uptake of elastomers in $\mathrm{PBS}$ at $37^{\circ} \mathrm{C}$. For elastomers names, please refer to Table 1 (data are expressed as means \pm SD and correspond to measurements in triplicate).

Degradation in PBS was in agreement with the water uptake results. As shown in Figure 2, elastomers $\mathrm{E}_{12}$ (full lines), due to their low water uptake, presented an induction period superior to one month where no evolution of weight loss was detected. Following this initial step, weight loss was fast with values in the range $75-80 \%$ after three months, and $89-98 \%$ after six months. In opposition, a rapid weight loss was observed right from the beginning for $\mathrm{E}_{3.5}$ (dashed lines), with already between $14 \%$ and $21 \%$ of loss after one month and almost complete degradation at three months (95-100\%). No real difference was found between the crosslinkers. With exception of $\mathrm{E}_{3.5-\mathrm{P}-\mathrm{A}}$ that presents higher deviation for the two first points at one and two weeks, it can be concluded that $\mathrm{E}_{3.5}$ elastomers present a linear degradation over 
a three-month period, whereas $\mathrm{E}_{12}$ elastomers present a typical sigmoidal degradation over a six-month period.

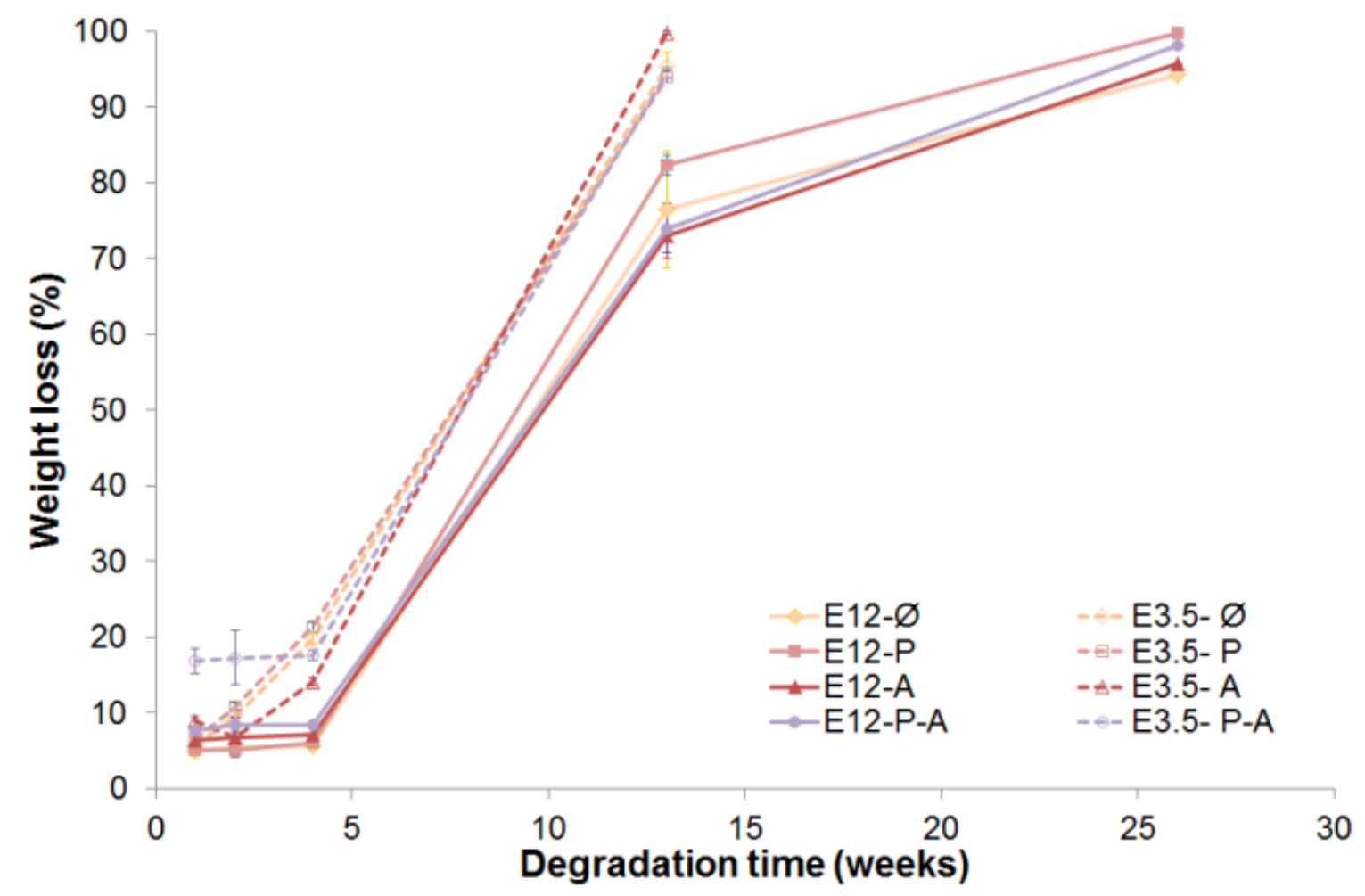

Figure 2. Weight loss vs. degradation time for elastomers in $\mathrm{PBS}$ at $37^{\circ} \mathrm{C}$ (data are expressed as means $\pm \mathrm{SD}$ and correspond to measurements in triplicate)

Following these results, we were interested in evaluating the degradability of some elastomers prepared with diallyl sulfide that present reducible crosslinks in the form of disulfide bonds. It is to note that redox responsive materials have to date mainly been developed for responsive drug delivery systems that hold great promise as a tool for improving the pharmacokinetic properties of drug compounds. However, although redox responsive drug delivery approaches are mainly based on nanoobjects (nanogels, micelles, nanospheres...), ${ }^{[37]}$ drug eluting bulk biomaterials may also be key materials in the frame of tissue engineering and medical devices. In fact such bulk redox-sensitive materials, especially elastomers, would allow the modulation or even the control of the degradation and drug release kinetics of drug loaded scaffolds. 
Glutathione is considered to be the major thiol-disulfide redox buffer of the cell with physiological average GSH concentrations in the range $1-11 \mathrm{mM}^{[32,33]}$ To evaluate the bioreducibility of the elastomers, low molecular weight allyl sulfide-containing elastomers $\left(\mathrm{E}_{3.5-\mathrm{A}}\right)$ were degraded in presence of GSH $(10 \mathrm{mM})$ using conditions of the literature. ${ }^{[50]}$ Weight loss as a function of the presence of GSH was followed over 1 month, with fresh degradation medium being used at each time point (Figure 3). Under these conditions, the degradation of $E_{3.5-\mathrm{A}}$ was not significantly impacted by the presence of $10 \mathrm{mM} \mathrm{GSH}$ in the degradation medium. This result could appear as unexpected considering the reported GSH redox-sensitive nanoscales assemblies or hydrogels using similar conditions. ${ }^{[37,40-43]}$ One should however note that in the present study, the bulky nature of the elastomers and their hydrolytic degradation ability may explain this result. In more details, for the reported redoxsensitive hydrogels of PNiPAMM or PEG, there is no increase in acidity due to degradation of the material. On the other hand, for the nanosized redox-sensitive micelles and nanoparticles where a rapid reduction is aimed, the reducible groups are located at the surface and are highly accessible to the GSH. We therefore hypothesize that in our case, the absence of significant effect of GSH is due to a combination of factors: i) the limited stability and activity of $\mathrm{GSH}$ at $37^{\circ} \mathrm{C}$ under aerobic and acidic conditions, ${ }^{[51-53]}$ ii) the bulkiness of the elastomers that decreases the accessibility to the reducible disulfide and may yield a slightly more acidic microenvironment as a result of the hydrolytic degradation of the PLA segments.

These points should be further elucidated in future dedicated studies, however to further evaluate the redox responsiveness of our reducing elastomer, 2-mercaptoethanol was selected as an alternative reducing agent. The use of reducers others than GSH, including dithiothreitol or 2-mercaptoethanol, is classically reported in the literature to evaluate redox responsiveness of biomaterials. ${ }^{[40,54,55]}$ For the later, it has been proposed as a GSH model due to its standard 
redox potential $\left(\mathrm{E}_{0}=-0.26 \mathrm{~V}\right)$ comparable to the standard redox potential of $\mathrm{GSH}\left(\mathrm{E}_{0}=-\right.$ $0.24 \mathrm{~V}) .{ }^{[56-58]}$ Like for GSH experiment, low molecular weight allyl disulfide containing elastomers $\left(\mathrm{E}_{3.5-\mathrm{A}}\right)$ were degraded in presence of $10 \mathrm{mM}$ 2-mercaptoethanol (Figure 3). After 1 month, a $62 \%$ weight loss was obtained in the presence of 2-mercaptoethanol, against $14 \%$ in PBS. This result confirms the potential of these redox sensitive elastomers to modulate the polyester-based elastomers degradation and eventually drug release profiles. Future studies focusing on anaerobic conditions applied to the all range of reducible elastomers should follow.

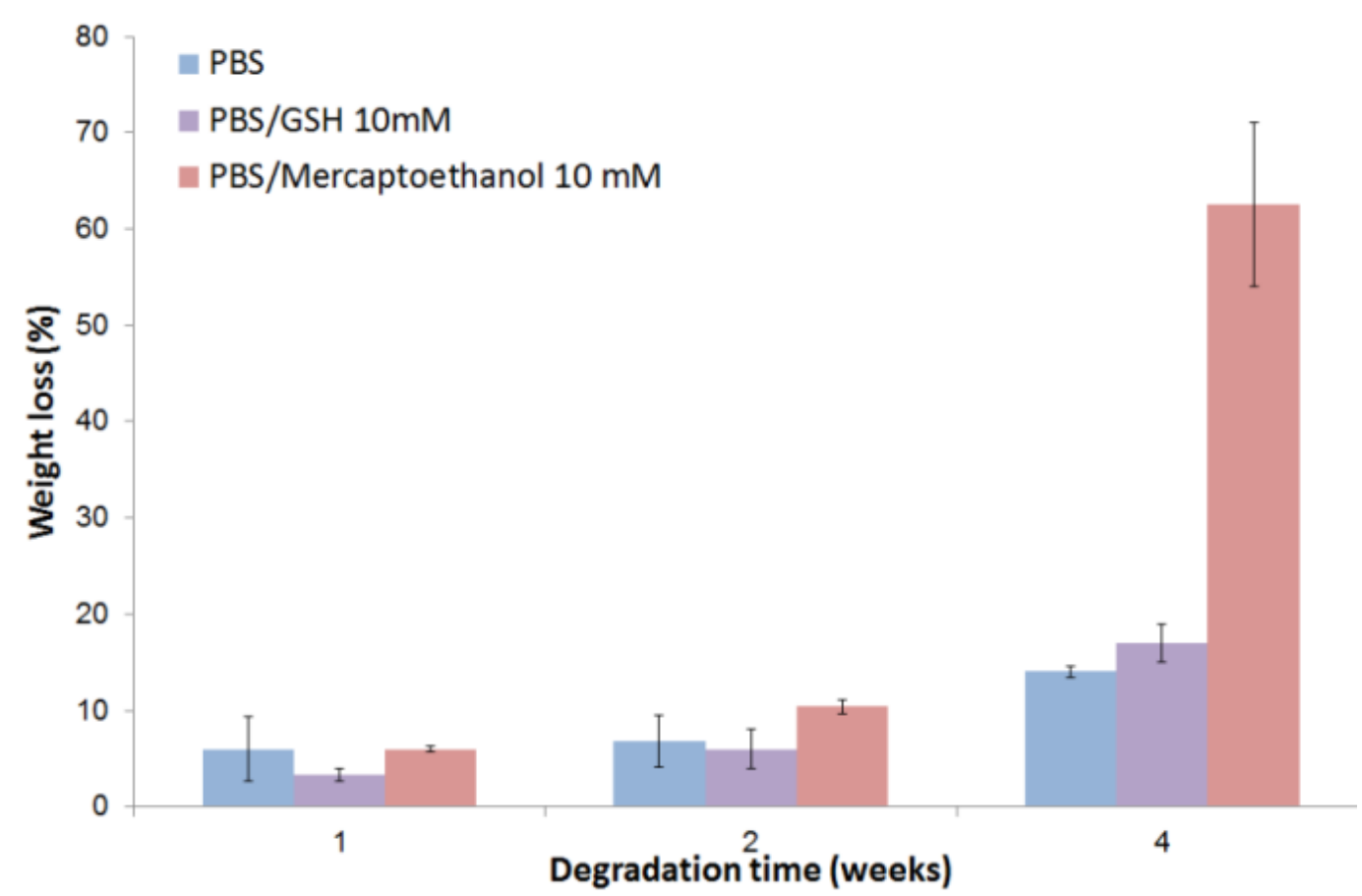

Figure 3. Compared weight losses of reducible $E_{3.5-\mathrm{A}}$ elastomer in PBS, PBS/GSH $(10 \mathrm{mM})$ or PBS/2-mercaptoethanol $(10 \mathrm{mM})$ (data are expressed as means $\pm \mathrm{SD}$ and correspond to measurements in triplicate).

\subsection{Drug loaded elastomers: properties and drug release}

The potential of degradable elastomers as drug eluting biomaterials was finally evaluated with the simplest formulations, ie. $\mathrm{E}_{12-\varnothing}$ and $\mathrm{E}_{3.5-\varnothing .}$. Ibuprofen was chosen as an anti-inflammatory model drug compound and was loaded in the elastomers by soaking them in a $4 \mathrm{wt} \%$ 
ibuprofen solution. Ibuprofen loadings were evaluated by extraction of the drug in acetone followed by HPLC quantification. Drug loadings of $3.6 \pm 0.6 \mathrm{wt} \%$ and $3.1 \pm 0.6 \mathrm{wt} \%$ were calculated for $\mathrm{E}_{3.5-\varnothing}$ and $\mathrm{E}_{12-\varnothing,}$, respectively.

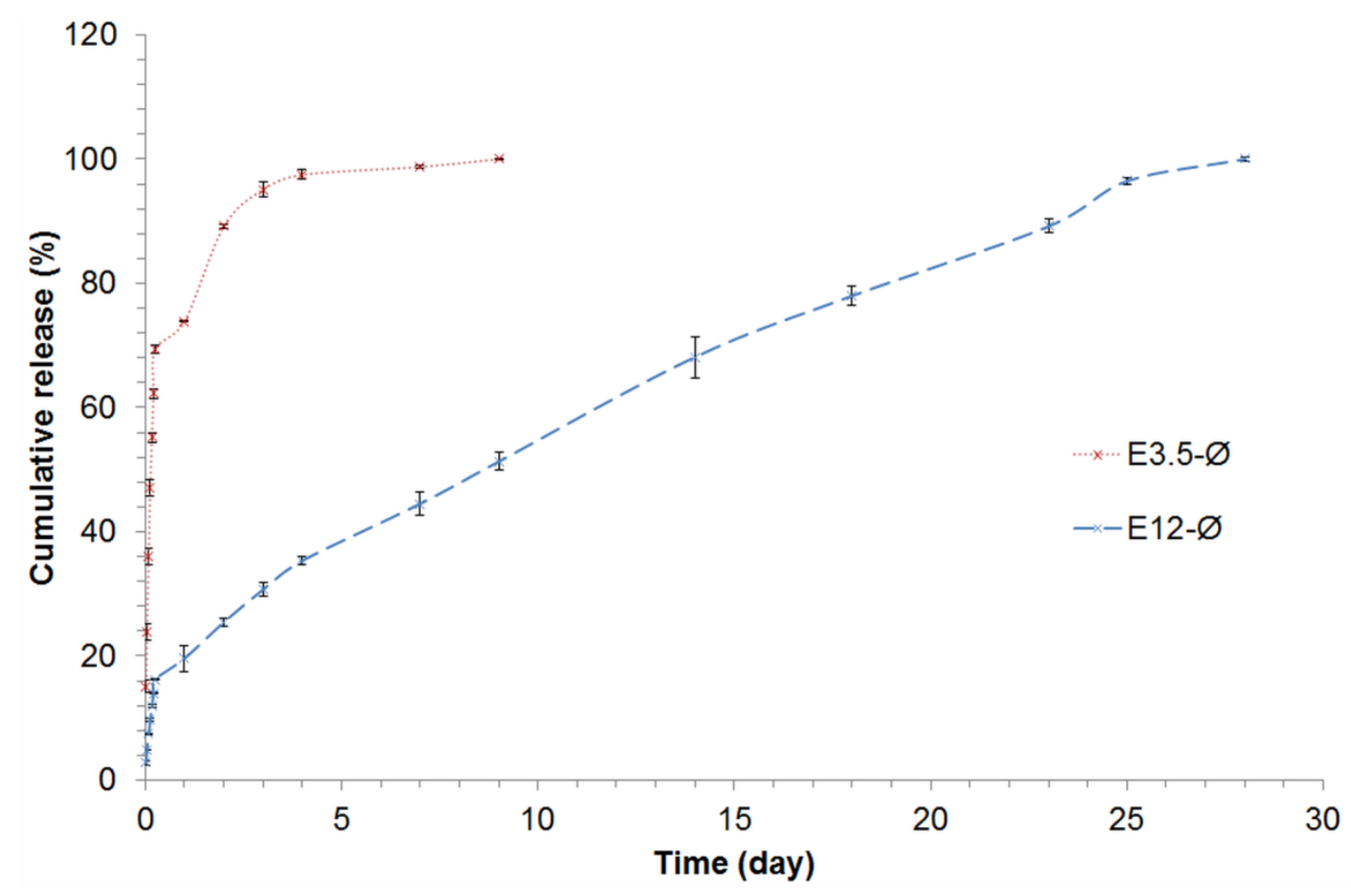

Figure 4. Ibuprofen release profiles from $E_{3.5-\varnothing}$ and $E_{12-\varnothing}$ elastomers (data are expressed as means \pm SD and correspond to measurements with $n=6$ ).

Release studies were performed in PBS (Figure 4). For the $\mathrm{E}_{12-\varnothing}$ elastomer, a $16 \%$ burst release is observed during the first hours, which may represent drug that was not distributed homogeneously throughout the elastomer and that was located near the surface of the samples. The burst release is followed by a slow and nearly constant release rate until day 28 . Figures 2 and 4 show that the ibuprofen release occurs at a much faster rate than the degradation rate, indicating that the release is most likely diffusion controlled from the $\mathrm{E}_{12-\varnothing}$ elastomer, similar to previous observations on the release of biologically active agents from PLA-based elastomers. ${ }^{[7]}$ 
Compared to the $\mathrm{E}_{12-\varnothing}$ elastomer, the ibuprofen release from the $\mathrm{E}_{3.5-\varnothing}$ elastomer is significantly faster. A $70 \%$ burst release of is observed, followed by a constant release rate until day 2, after which the rate levels off until the release is complete on day 5 . The fast release may be due to the high water uptake of the hydrophilic $\mathrm{E}_{3.5-\varnothing}$ elastomer after immersion in PBS (Figure 1) and the accompanying rapid weight loss (Figure 2). The loss of material after degradation and the high degree of swelling most likely result in a higher diffusion coefficient for ibuprofen in the $E_{3.5-\varnothing}$ elastomer in comparison with the $E_{12-\varnothing}$ elastomer.

\subsection{Elastomers cytocompatibility}

An evaluation of cells proliferation was performed on elastomers to assess their cytocompatibility and evaluate their suitability for cell culture and cell-contacting biomedical applications. Tests were conducted on the L929 fibroblast cell line, as recommended by standard ISO 10993-5:2009. ${ }^{[59]}$ Figure 5 shows the proliferation of L929 murine fibroblasts over a week on the elastomeric films and TCPS positive control.

A clear dependence over the hydrophilic/hydrophobic balance of the prepolymers is demonstrated. It is clearly visible that L929 fibroblasts adhered and proliferated on the more hydrophobic elastomers, ie. the $\mathrm{E}_{12}$ series, whereas proliferation of cells was very limited on the more hydrophilic elastomers of the $E_{3.5}$ series. Such dependence is in accordance with previous studies of Garric et al. on PLA- $b$-PEG- $b$-PLA skin substitutes. ${ }^{[60]}$ Figure 5 also shows two distinct periods for L929 proliferation. From day 1 to day 3 proliferation on the $\mathrm{E}_{12}$ series is comparable or superior to the one obtained on TCPS control (see close up in Figure S2). However at day 7 a stronger proliferation is observed on the TCPS positive control compared to $\mathrm{E}_{12}$ elastomers where proliferation is about twice lower than on TCPS. Coming to a more detailed analysis of results, the combination of both crosslinkers turns to be 
beneficial with higher proliferation observed on $\mathrm{E}_{12-\mathrm{P}-\mathrm{A}}$ and $\mathrm{E}_{3.5-\mathrm{P}-\mathrm{A}}$ samples compared to the other elastomers of the same series (Figure S2). It is even remarkable that at all time points, from day 1 to day 3, $\mathrm{E}_{12-\mathrm{P}-\mathrm{A}}$ shows ca. $20 \%$ higher proliferation than TCPS control. This tendency is more pronounced at early stages and is totally inverted at day 7 . These results confirm that the proposed elastomers, depending on their hydrophilic/hydrophobic balance are either suitable for the growth of fibroblasts ( $E_{12}$ hydrophobic series), or behave more like antiadhesion/antiproliferation materials ( $\mathrm{E}_{3.5}$ hydrophilic series). Depending on the target application, this family of elastomers offers therefore opportunities for the design and the development of medical devices.

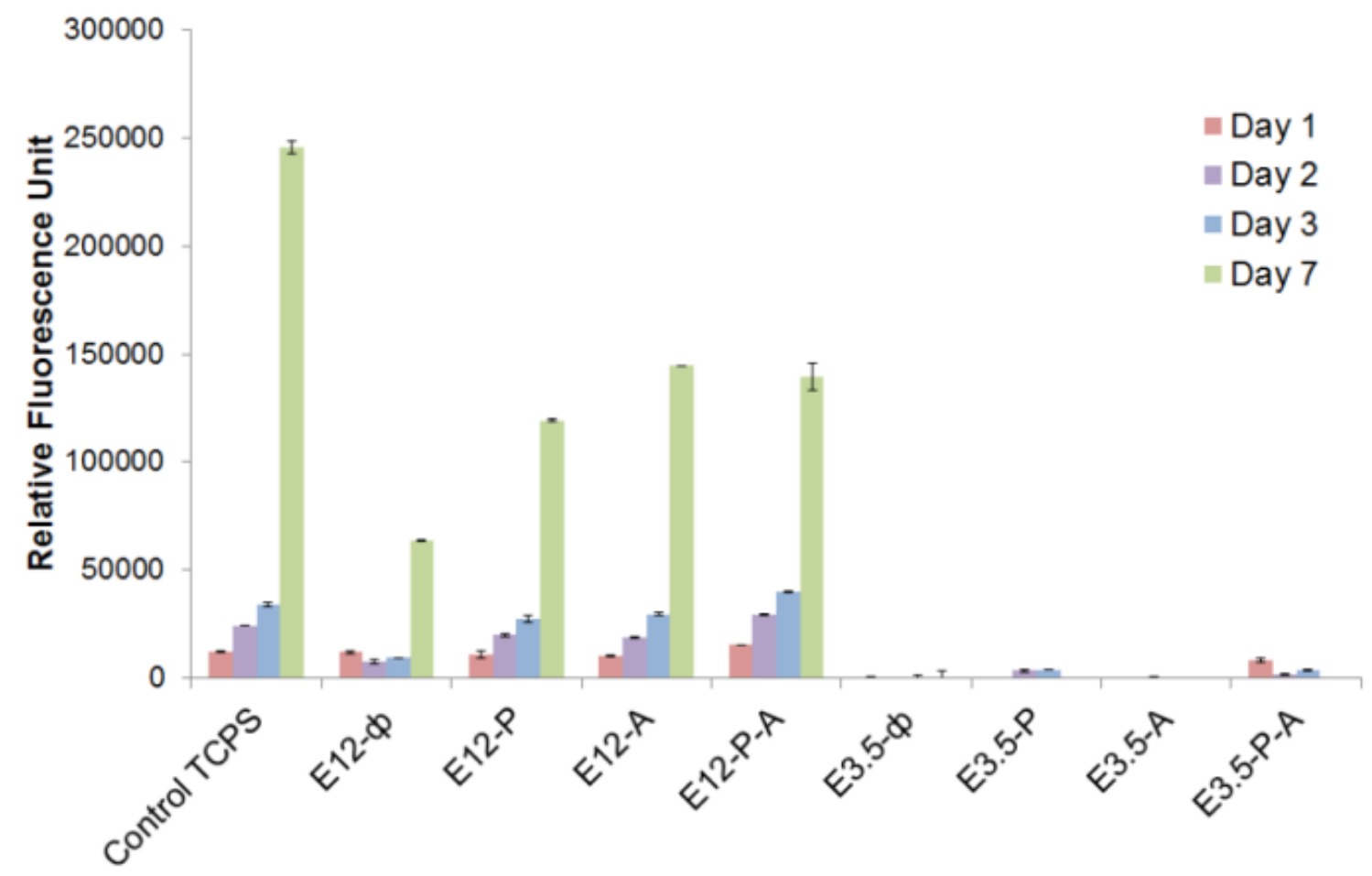

Figure 5. L929 fibroblasts proliferation on elastomers compared to TCPS control at 1, 2, 3 and 7 days (data are expressed as means $\pm \mathrm{SD}$ and correspond to measurements in triplicate). 


\section{CONCLUSION}

PLA/PEG-based elastomers have been efficiently prepared using thiol-ene or methacrylate photo-curing of PLA- $b$-PEG- $b$-PLA triblock copolymers. Depending on the network characteristics, in particular the macromolecular parameters of the copolymers used, it was possible to modulate the elastomers mechanical properties with elastic limits in the range 10 to $150 \%$ and Young's moduli in the range 0.5 to $2.2 \mathrm{MPa}$. Complete and quasi-linear degradation was obtained after 3 months in the case of low molecular weight pre-polymers and after 6 months, including a 1 month induction period, in the case of higher molecular weight pre-polymers. In the frame of stimuli-responsive materials, it was also demonstrated with the $\mathrm{E}_{3.5-\mathrm{A}}$ that disulfide-containing elastomers may be used as redox-sensitive degradable systems to modulate/trigger degradation with a $400 \%$ increase of weight loss in the presence of 2-mercaptoethanol compared to pure PBS. GSH responsiveness was not observed in the present work, probably because of the known lower stability of GSH in acidic medium or aerobic conditions. Further studies on this particular point should therefore follow. Considering the use of such degradable elastomeric biomaterials for the development of temporary and drug eluting medical devices, the simplest formulations $\mathrm{E}_{3.5-\varnothing}$ and $\mathrm{E}_{12-\varnothing}$ were selected for a proof of concept study. Their loading ability ( 3-3.5 wt\%) with the antiinflammatory ibuprofen and complete drug release over 5 or 30 days as a function of the prepolymer used were shown. It was finally shown that depending on the formulation of the elastomers and especially the hydrophilicity, opposite behaviours could be reached in terms of cells proliferation, that is pro-proliferative or anti-proliferative materials. It is our belief that this combination of features may allow one to select the more appropriate elastomer with respect to the final application and that they offer opportunities for the design and the development of innovative medical devices or tissue engineering scaffolds. 


\section{ACKNOWLEDGMENT}

The authors wish to thank the Erasmus program for Simona Rupnik's fellowship, the Marie

Skłodowska-Curie Individual Fellowship \#660953 - LX micelles for Sytze Buwalda fellowship and Sylvie Hunger for SEC and NMR analyses.

\section{REFERENCES}

[1] Q. Y. Liu, L. Jiang, R. Shi, L. Q. Zhang, Prog. Polym. Sci. 2012, 37, 715.

[2] Q. Z. Chen, S. L. Liang, G. A. Thouas, Prog. Polym. Sci. 2013, 38, 584.

[3] D. V. Barrett, W. Luo, M. N. Yousaf, Polym.Chem. 2010, 1, 296.

[4] D. A. Olson, S. E. A. Gratton, J. M. DeSimone, V. V. Sheares, J. Am. Chem. Soc. 2006, $128,13625$.

[5] A. O. Helminen, H. Korhonen, J. V. Seppala, J. Appl. Polym. Sci. 2002, 86, 3616.

[6] F. Gu, R. Neufeld, B. Amsden, J. Control. Release 2007, 117, 80.

[7] F. Y. Guo, W. Zhang, X. H. Pei, X. Shen, Q. Y. Yan, W. Y. Hong, G. S. Yang, J. Appl. Polym. Sci. 2016, 133.

[8] B. G. Amsden, Expert Opin. Drug Del. 2008, 5, 175.

[9] M. A. Shaker, H. M. Younes, J. Control. Release 2015, 217, 10.

[10] I. S. Tobias, H. Lee, G. C. Engelmayr, D. Macaya, C. J. Bettinger, M. J. Cima, J. Control. Release 2010, 146, 356.

[11] X. Y. Zhao, L. Sun, M. Z. Wang, Z. Y. Sun, J. Xie, Polym. Int. 2014, 63, 393.

[12] E. Bat, B. H. M. Kothman, G. A. Higuera, C. A. van Blitterswijk, J. Feijen, D. W. Grijpma, Biomaterials 2010, 31, 8696.

[13] J. P. Bruggeman, B. J. de Bruin, C. J. Bettinger, R. Langer, Biomaterials 2008, 29, 4726.

[14] S. A. Guelcher, Tissue Eng. Pt. B-Rev. 2008, 14, 3. 
[15] J. Dey, H. Xu, J. H. Shen, P. Thevenot, S. R. Gondi, K. T. Nguyen, B. S. Sumerlin, L. P. Tang, J. Yang, Biomaterials 2008, 29, 4637.

[16] W. S. Wang, P. Ping, H. J. Yu, X. S. Chen, X. B. Jing, J. Polym. Sci. Pol. Chem. 2006, $44,5505$.

[17] J. B. Zeng, Y. D. Li, Q. Y. Zhu, K. K. Yang, X. L. Wang, Y. Z. Wang, Polymer 2009, $50,1178$.

[18] J. Yang, A. R. Webb, S. J. Pickerill, G. Hageman, G. A. Ameer, Biomaterials 2006, 27, 1889.

[19] A. O. Helminen, H. Korhonen, J. V. Seppala, Macromol. Chem. Phys. 2002, 203, 2630.

[20] H. C. Zhao, G. A. Ameer, J. Appl. Polym. Sci. 2009, 114, 1464.

[21] C. L. E. Nijst, J. P. Bruggeman, J. M. Karp, L. Ferreira, A. Zumbuehl, C. J. Bettinger, R. Langer, Biomacromolecules 2007, 8, 3067.

[22] B. G. Amsden, G. Misra, F. Gu, H. M. Younes, Biomacromolecules 2004, 5, 2479.

[23] H. Blattmann, M. Fleischer, M. Bahr, R. Mulhaupt, Macromol. Rapid Comm. 2014, 35, 1238.

[24] C. Carre, L. Bonnet, L. Averous, RSC Adv. 2014, 4, 54018.

[25] A. Leroy, B. Nottelet, C. Bony, C. Pinese, B. Charlot, X. Garric, D. Noel, J. Coudane, Biomater. Sci. 2015, 3, 617.

[26] C. Pinese, A. Leroy, B. Nottelet, C. Gagnieu, J. Coudane, X. Garric, J. Biomed. Mater. Part B 2016.

[27] A. Harrane, A. Leroy, H. Nouailhas, X. Garric, J. Coudane, B. Nottelet, Biomed. Mater. 2011, 6, 065006.

[28] A. Leroy, A. Al Samad, X. Garric, S. Hunger, D. Noel, J. Coudane, B. Nottelet, RSC $A d v . \mathbf{2 0 1 4}, 4,32017$. 
[29] J. E. Dumas, T. Davis, G. E. Holt, T. Yoshii, D. S. Perrien, J. S. Nyman, T. Boyce, S. A. Guelcher, Acta Biomater. 2010, 6, 2394.

[30] M. A. Meyers, P. Y. Chen, A. Y. M. Lin, Y. Seki, Prog. Mater. Sci. 2008, 53, 1.

[31] A. Leroy, C. Pinese, C. Bony, X. Garric, D. Noel, B. Nottelet, J. Coudane, Mat. Sci. Eng. C-Mater. 2013, 33, 4133.

[32] H. F. Gilbert, "Molecular and Cellular Aspects of Thiol Disulfide Exchange", in Adv. Enzymol. Ramb., 1990, p. 69.

[33] C. V. Smith, D. P. Jones, T. M. Guenthner, L. H. Lash, B. H. Lauterburg, Toxicol. Appl. Pharm. 1996, 140, 1.

[34] J. M. Hansen, C. Harris, Bba-Gen. Subjects 2015, 1850, 1527.

[35] N. Traverso, R. Ricciarelli, M. Nitti, B. Marengo, A. L. Furfaro, M. A. Pronzato, U. M. Marinari, C. Domenicotti, Oxid. Med. Cell Longev. 2013.

[36] R. Cheng, F. Feng, F. H. Meng, C. Deng, J. Feijen, Z. Y. Zhong, J. Control. Release 2011, 152, 2 .

[37] M. Huo, J. Yuan, L. Tao, Y. Wei, Polym. Chem. 2014, 5, 1519.

[38] Z. Q. Lei, H. P. Xiang, Y. J. Yuan, M. Z. Rong, M. Q. Zhang, Chem. Mater. 2014, 26, 2038.

[39] B. T. Michal, C. A. Jaye, E. J. Spencer, S. J. Rowan, ACS Macro Lett. 2013, 2, 694.

[40] H. Lee, T. G. Park, Polym. J. 1998, 30, 976.

[41] M. Kar, Y. R. V. Shih, D. O. Velez, P. Cabrales, S. Varghese, Biomaterials 2016, 77, 186.

[42] B. D. Fairbanks, S. P. Singh, C. N. Bowman, K. S. Anseth, Macromolecules 2011, 44, 2444.

[43] M. W. Tibbitt, A. M. Kloxin, L. A. Sawicki, K. S. Anseth, Macromolecules 2013, 46, 2785 
[44] B. Nottelet, G. Tambutet, Y. Bakkour, J. Coudane, Polym. Chem. 2012, 3, 2956.

[45] T. Ariga, T. Seki, Biofactors 2006, 26, 93.

[46] H. F. Lu, C. C. Sue, C. S. Yu, S. C. Chen, G. W. Chen, J. G. Chung, Food Chem. Toxicol. 2004, 42, 1543.

[47] L. Yi, Q. Su, Food Chem. Toxicol. 2013, 57, 362.

[48] F. Li, S. M. Li, M. Vert, Macromol. Biosci. 2005, 5, 1125.

[49] ISO 37:2011, "Rubber, vulcanized or thermoplastic -- Determination of tensile stressstrain properties", 2011.

[50] H. C. Kim, E. Kim, T. L. Ha, S. W. Jeong, S. G. Lee, S. J. Lee, B. Lee, Colloid. Surface B 2015, 127, 206.

[51] M. Z. Hoffman, E. Hayon, J. Am. Chem. Soc. 1972, 94, 7950.

[52] M. Ikebuchi, A. Kashiwagi, T. Asahina, Y. Tanaka, Y. Takagi, Y. Nishio, H. Hidaka, R. Kikkawa, Y. Shigeta, Metabolism 1993, 42, 1121.

[53] T. Yamamoto, K. Ishihara, "Stability of Glutathione in Solution", in Developments in Food Engineering, T. Yano, R. Matsuno, and K. Nakamura, Eds., Springer US, 1994, p. 209. [54] C. Cui, P. Yu, M. Wu, Y. Zhang, L. Liu, B. Wu, C. X. Wang, R. X. Zhuo, S. W. Huang, Colloid. Surface B 2015, 129, 137.

[55] Q. L. Yang, L. J. Tan, C. Y. He, B. Y. Liu, Y. H. Xu, Z. G. Zhu, Z. F. Shao, B. Gong, Y. M. Shen, Acta Biomater. 2015, 17, 193.

[56] C. E. Aitken, R. A. Marshall, J. D. Puglisi, Biophys. J. 2008, 94, 1826.

[57] S. T. Y. Hui, A. M. Andres, A. K. Miller, N. J. Spann, D. W. Potter, N. M. Post, A. Z. Chen, S. Sachithanantham, D. Y. Jung, J. K. Kim, R. A. Davis, P. Natl. Acad. Sci. USA 2008, $105,3921$.

[58] P. C. Jocelyn, Eur. J. Biochem. 1967, 2, 327. 
[59] ISO 10993-5:2009, "Biological evaluation of medical devices -- Part 5: Tests for in vitro cytotoxicity", 2009.

[60] X. Garric, H. Garreau, M. Vert, J. P. Moles, J. Mater. Sci.-Mater. M. 2008, 19, 1645. 


\section{Text for the Table of Contents}

Degradable elastomers for soft tissue-related medical devices are proposed. These PLA-PEG based biomaterials have mechanical properties suitable for soft tissue applications, and feature a bimodal redox/hydrolytic degradation. Besides, they offer drug loading and drug release ability, as well as a tunable cell compatibility that makes them anti- or pro-proliferative biomaterials.

\section{TOC graphic}

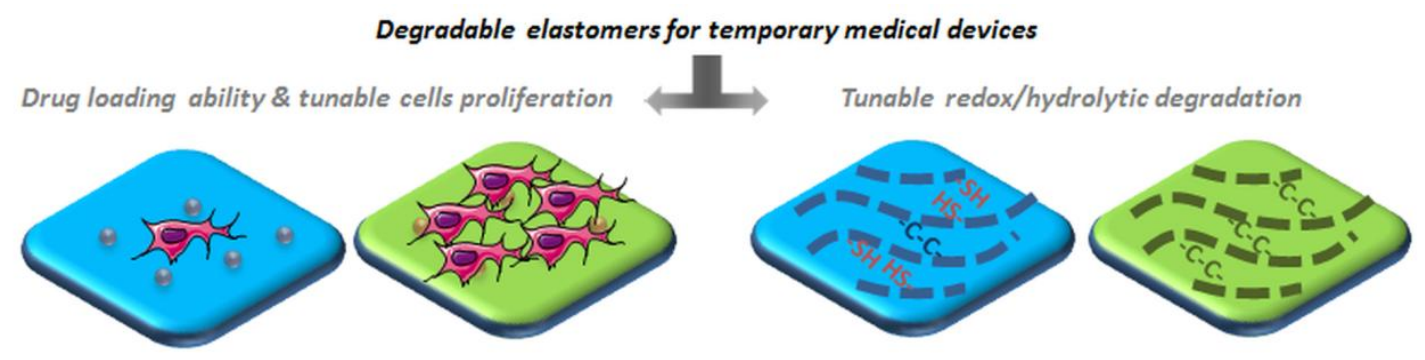




\section{Supplementary information}

\section{Redox reducible and hydrolytically degradable PEG-PLA elastomers as}

biomaterial for temporary drug eluting medical devices

Simona Rupnik, Sytze Buwalda, Stéphane Dejean, Audrey Bethry, Xavier Garric, Jean Coudane, Benjamin Nottelet*

Institute of Biomolecules Max Mousseron (IBMM) UMR 5247, Department of Artificial Biopolymers, CNRS, University of Montpellier, ENSCM.

Faculté de Pharmacie, 15 avenue Charles Flahault BP14491, 34093 Montpellier cedex 5, France

* benjamin.nottelet@umontpellier.fr 


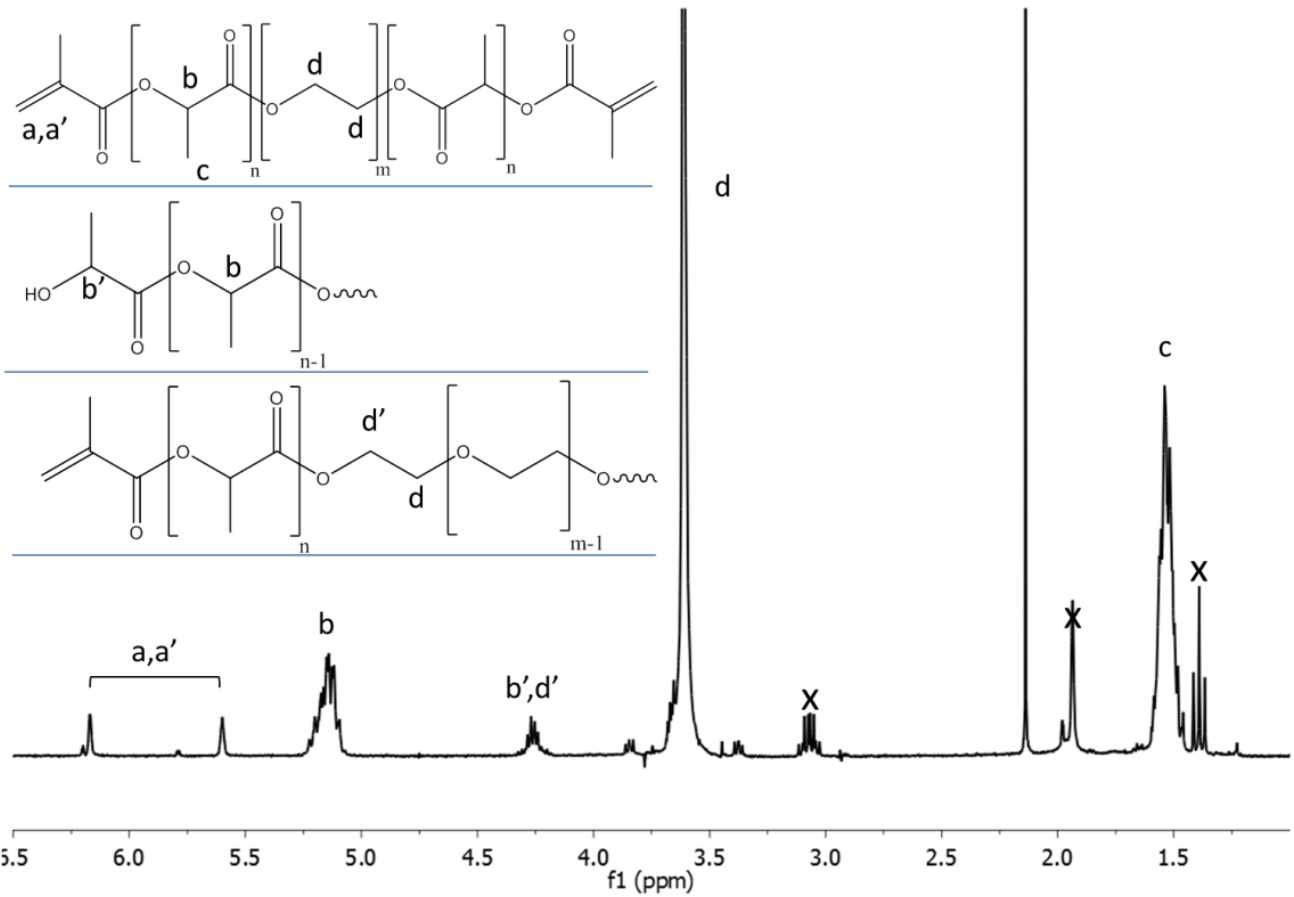

Figure S1. ${ }^{1} \mathrm{H}$ NMR $(300 \mathrm{MHz} ; \mathrm{CDCl} 3)$ of methacrylated $\mathrm{PLA}_{9}-\mathrm{PEG}_{2 \mathrm{k}}-\mathrm{PLA}_{9}$ copolymer. Crosses correspond to residual solvents and triethylammonium salt. 


\section{Procedure: Ibuprofen standard curve}

Ibuprofen solutions with concentrations in the range $2 \mu \mathrm{g} / \mathrm{mL}$ to $1000 \mu \mathrm{g} / \mathrm{mL}$ were prepared in PBS/EtOH (50:50). The analyses were carried out by HPLC (WatersTM 717 plus Autosampler) using a 50:50 mixture of water: TFA (1:1000) and acetonitrile: TFA (1:1000) at flow rate $1 \mathrm{~mL} / \mathrm{min}$ and a photodiode array detector $\left(\lambda_{\max }=264 \mathrm{~nm}\right)$.

\begin{tabular}{c|ccc|} 
Concentration $(\boldsymbol{\mu g} / \mathbf{m l})$ & $\begin{array}{c}\text { Area } \\
\left(\boldsymbol{\mu} \mathbf{V}^{*} \mathbf{s e c}\right)\end{array}$ & $\begin{array}{c}\text { Ret. Time } \\
(\mathbf{m i n})\end{array}$ & $\begin{array}{c}\text { Height } \\
(\boldsymbol{\mu \mathbf { V }})\end{array}$ \\
\hline 1000 & 8634198 & 2,721 & 1462565 \\
500 & 4397773 & 2,733 & 851809 \\
250 & 2202354 & 2,736 & 461141 \\
100 & 849546 & 2,757 & 185847 \\
50 & 83483 & 2,762 & 19216 \\
10 & 51293 & 2,759 & 11626 \\
2 & 17861 & 2,766 & 4246
\end{tabular}

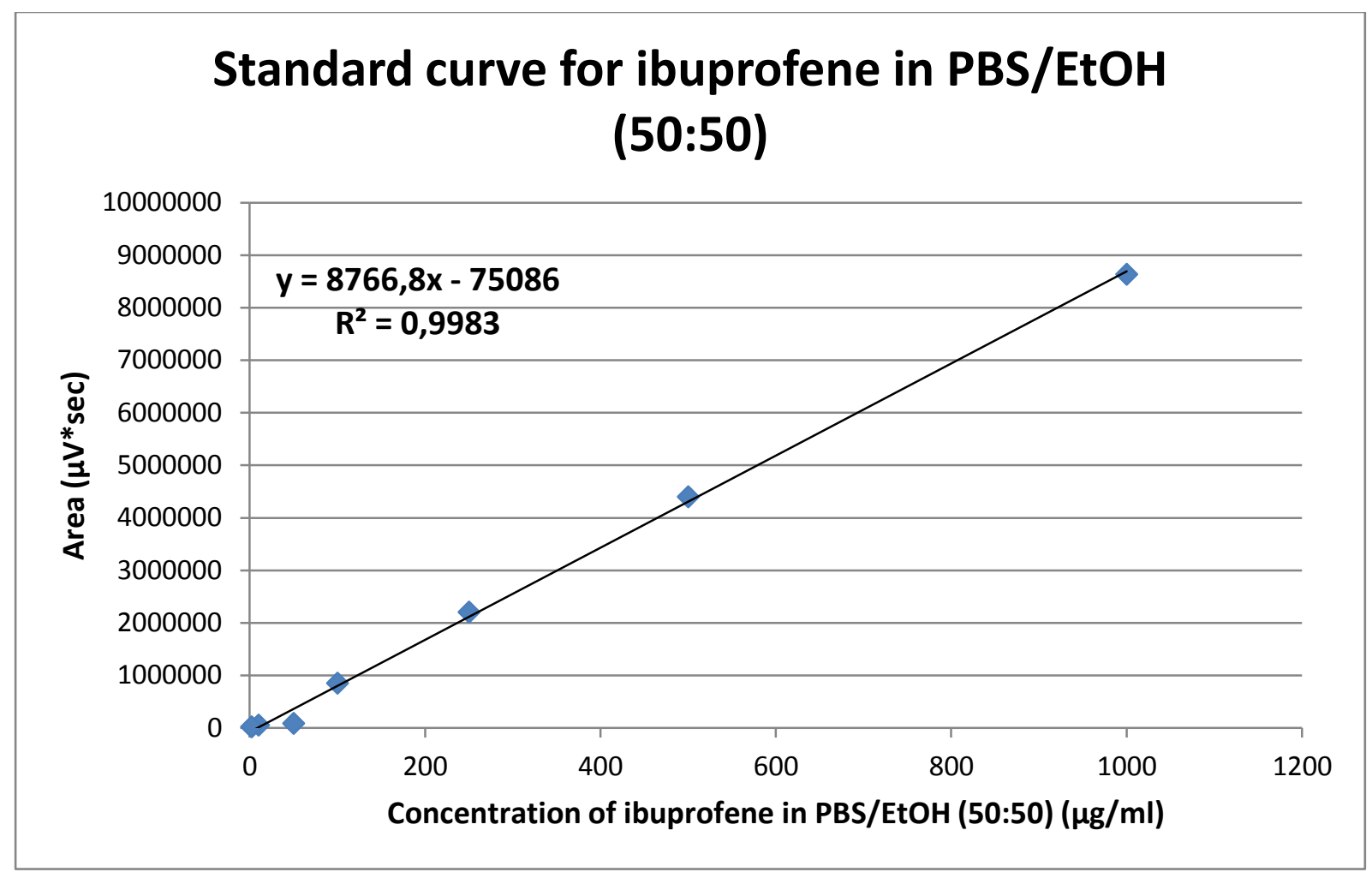




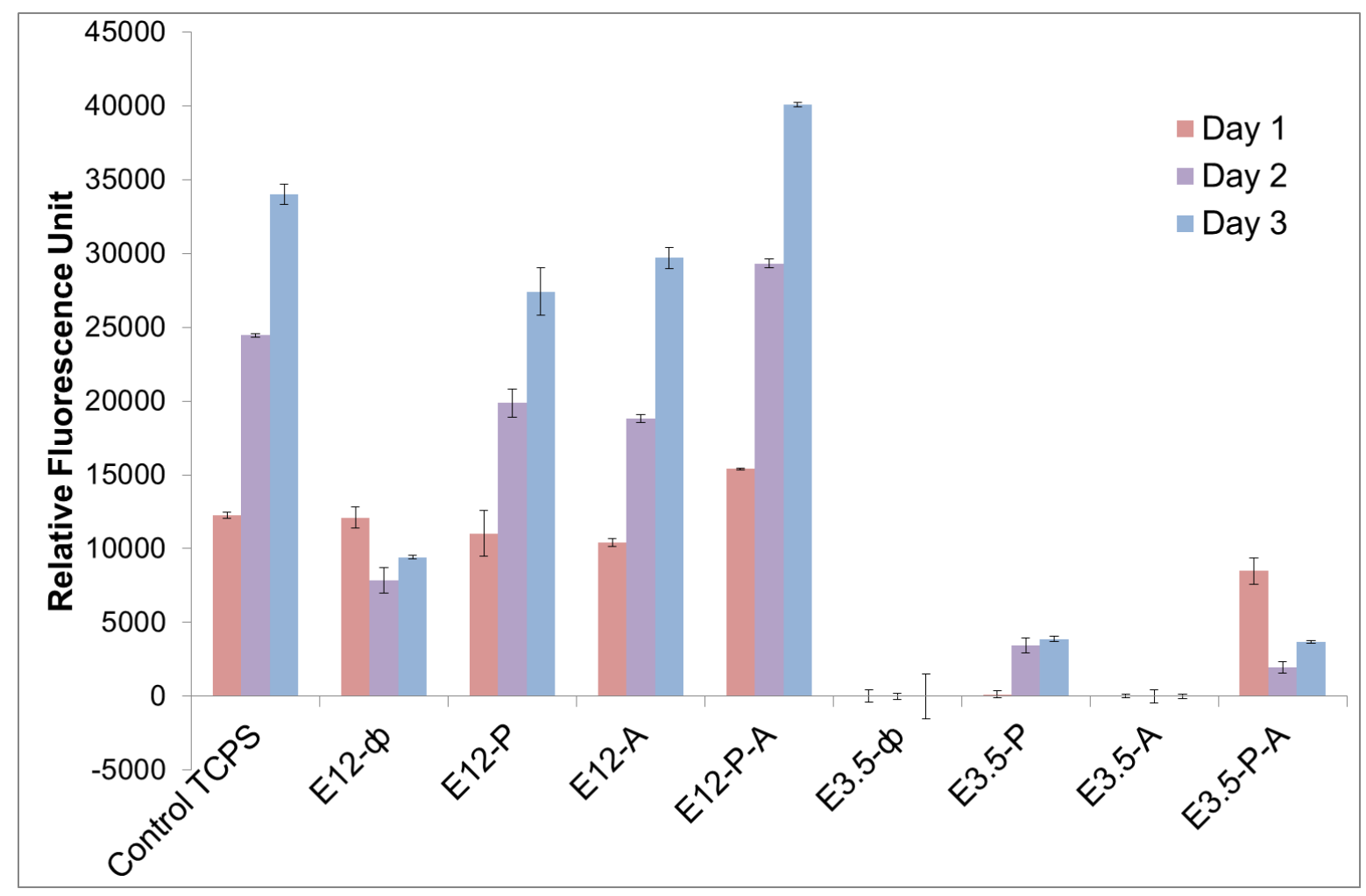

Figure S2. L929 fibroblasts proliferation on elastomers compared to TCPS control at 1, 2 and 3 days (data are expressed as means \pm SD and correspond to measurements in triplicate). 
Table S1. Characterizations of copolymers

\begin{tabular}{|c|c|c|c|c|c|c|c|}
\hline $\begin{array}{c}\text { Sample } \\
\text { name }\end{array}$ & Chain ends & $\begin{array}{c}\text { Targeted } \\
\text { EG/LA }\end{array}$ & $\begin{array}{c}\text { Targeted } \\
\text { Mn } \\
(\mathrm{g} / \mathrm{mol})\end{array}$ & $\begin{array}{l}\mathrm{Mn}_{\mathrm{NMR}} \\
(\mathrm{g} / \mathrm{mol})\end{array}$ & $\begin{array}{l}\mathrm{Mn}_{\mathrm{SEC}}{ }^{*} \\
(\mathrm{~g} / \mathrm{mol})\end{array}$ & 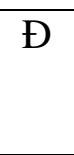 & $\begin{array}{c}\text { Methacrylation } \\
(\%)\end{array}$ \\
\hline $\begin{array}{l}\mathrm{PLA}_{9-} \\
\mathrm{PEG}_{2 \mathrm{k}^{-}} \\
\mathrm{PLA}_{9}\end{array}$ & hydroxyl & 2.5 & 3296 & 3300 & 4700 & 1.1 & - \\
\hline $\begin{array}{l}\mathrm{PLA}_{9-} \\
\mathrm{PEG}_{2 \mathrm{k}^{-}} \\
\mathrm{PLA}_{9}\end{array}$ & methacrylate & 2.5 & 3296 & 3580 & 5700 & 1.1 & $100 \%$ \\
\hline $\begin{array}{l}\text { PLA }_{62^{-}} \\
\text {PEG }_{1 k^{-}} \\
\text {PLA }_{62}\end{array}$ & hydroxyl & 0.2 & 10000 & 12300 & 9030 & 1.5 & - \\
\hline $\begin{array}{l}\text { PLA }_{62^{-}} \\
\text {PEG }_{1 k^{-}} \\
\text {PLA }_{62}\end{array}$ & methacrylate & 0.2 & 10000 & 12300 & 11800 & 1.4 & $70 \%$ \\
\hline
\end{tabular}

3

4 Table S2. Thermal properties of methacrylated pre-polymers and PEG

\begin{tabular}{cccc}
\hline Polymer & $\begin{array}{c}\mathrm{Tg} \\
\left({ }^{\circ} \mathrm{C}\right)\end{array}$ & $\begin{array}{c}\mathrm{Tm} \\
\left({ }^{\circ} \mathrm{C}\right)\end{array}$ & $\Delta \mathrm{H}(\mathrm{J} / \mathrm{g})$ \\
\hline PEG 2000 & $-60<$ & 56 & 235 \\
PLA $_{9}-\mathrm{PEG}_{2 \mathrm{k}}-\mathrm{PLA}_{9}$ & -37 & 40 & 50 \\
PLA $_{62}-\mathrm{PEG}_{1 \mathrm{k}}-\mathrm{PLA}_{62}$ & 15 & 29 & 62 \\
\hline
\end{tabular}

6 